\title{
Selective Nanotherapeutic Targeting of the Neutrophil Subset Mediating Inflammatory Injury
}

Kurt Bachmaier ${ }^{1}$, Andrew Stuart ${ }^{2}$, Zhigang Hong ${ }^{1}$, Yoshikazu Tsukasaki ${ }^{1}$, Abhalaxmi Singh ${ }^{1}$, Sreeparna Chakraborty ${ }^{1}$, Amitabha Mukhopadhyay ${ }^{1}$, Xiaopei Gao ${ }^{1}$, Mark Maienschein-Cline ${ }^{3}$, Prasad Kanteti ${ }^{2}$, Jalees Rehman ${ }^{1,4}$ and Asrar B. Malik ${ }^{1,2}$

${ }^{1}$ Department of Pharmacology and Regenerative Medicine and the Center for Lung and Vascular Biology,

The University of Illinois College of Medicine, E403, Medical Sciences Building, M/C 868, 835 S. Wolcott Avenue, Chicago, IL 60612

${ }^{2}$ Nano Biotherapeutics, Inc., 2201 W Campbell Park Dr, Chicago, IL 60612

${ }^{3}$ Research Informatics Core, The University of Illinois College of Medicine

${ }^{4}$ Division of Cardiology, Department of Medicine, The University of Illinois College of Medicine

Address correspondence to ABM (abmalik@uic.edu) and KB (kbachmai@uic.edu) 
Inflammatory tissue injury such as acute lung injury (ALI) is a disorder that leads to respiratory failure, a major cause of morbidity and mortality worldwide. Excessive neutrophil influx is a critical pathogenic factor in the development of ALI. Here, we identify the subset of neutrophils that is responsible for ALI and lethality in polymicrobial sepsis. The pro-inflammatory neutrophil subpopulation was characterized by its unique ability to endocytose albumin nanoparticles (ANP), upregulation of pro-inflammatory cytokines and chemokines as well as the excessive production of reactive oxygen species (ROS) in models of endotoxemia and septicemia. ANP delivery of the drug piceatannol, a spleen tyrosine kinase (Syk) inhibitor, to the susceptible subset of neutrophils, prevented ALI and mortality in mice subjected to polymicrobial infection. Targeted inhibition of Syk in ANP-susceptible neutrophils had no detrimental effect on neutrophil-dependent host defense because the subset of ANPlow neutrophils effectively controlled polymicrobial infection. The results show that neutrophil heterogeneity can be leveraged therapeutically to prevent ALI without compromising host defense. 


\section{Introduction}

Subsets of neutrophils differ markedly in their response to both homeostatic and inflammatory signals (1). Neutrophil heterogeneity is apparent in the lungs of naïve mice, where a large proportion is marginated in the microvasculature, where they may function as immune sentinels, while other neutrophils circulate unimpeded (2). Neutrophils are an essential component of the innate immune response to polymicrobial infection due to their ability to eliminate the infectious agents (3). However, neutrophils can also become pathogenic in diseases by promoting excessive inflammation such as in the case of acute lung injury (ALI), a main cause of morbidity and mortality worldwide (4). Excessive activation of neutrophils by bloodstream bacteria and their products, such as the bacterial endotoxin lipopolysaccharide (LPS), results in tissue damage and organ dysfunction (5). Therapeutic efforts of curbing this excessive neutrophilic inflammation have been frustratingly ineffective (6). Administration of nitric oxide, norepinephrine, low dose corticosteroids, prostaglandin E1, or recombinant activated protein C, when critically evaluated, did not significantly improve patient mortality (7). Moreover, neutralizing key inflammatory mediators such as the cytokines TNF- $\alpha$, and IL-1 $\beta$, or reactive oxygen species (ROS), has also failed (8). In experimental models, the elimination of neutrophils markedly decreases the severity of ALI (4). On the other hand, there is the risk of compromising host defense in the setting of global neutrophil impairment and deterioration of pulmonary function during recovery from neutropenia (9).

Targeting specific subsets of neutrophils could represent an optimal therapeutic approach if one could identify deleterious neutrophil subsets without compromising the subsets essential for host defense. The unique ability of neutrophils to rapidly change their phenotype and function according to changes in their microenvironment (10-14) is a manifestation of neutrophil heterogeneity, but the distinct roles of neutrophil subsets in the setting of sepsis or endotoxemia and not well understood. We hypothesized that subsets of neutrophils are primarily responsible for the maladaptive hyperinflammatory response that causes $\mathrm{ALI}$, multiple organ failure, and death. In the present study, we identified the subset of neutrophils that incorporated specially formulated albumin nanoparticles 
(ANP) as the subset that could be therapeutically targeted without impairing the elimination of bacteria in experimental septicemia.

\section{Results}

Heterogeneous response of neutrophils to endotoxin and septicemia. After i.v. injection of albumin nanoparticles (ANP) to naive mice, we observed ANP-uptake in liver and spleen, whereas lungs, heart and kidney remained mostly free of ANP (Supplemental Figure 1). In response to i.p. challenge with the endotoxin of Gram-negative bacteria, lipopolysaccharide (LPS), uptake of i.v.injected ANP in heart, kidney, liver and spleen did not increase compared to naïve mice. In lungs, however, ANP uptake increased significantly after LPS challenge (Supplemental Figure 1). Ly6G+ polymorphonuclear neutrophils (PMN) have the capacity to internalize ANP (15). We next determined whether uptake of ANP in the lung was restricted to Ly6G+ PMN and whether there was heterogeneity in the endocytosis of ANP among Ly6G+ PMN. In response to i.p. LPS, only $\mathrm{CD} 5^{+}$leukocytes endocytosed i.v. injected ANP whereas parenchymal cells (CD45 $\left.{ }^{\text {neg}}\right)$ did not (Figure 1A). ANP-endocytosis was restricted to $\mathrm{Ly} 6 \mathrm{G}^{+} \mathrm{PMN}$ and largely absent in $\mathrm{CD}^{+} 4^{+}$ monocytes/macrophages, NK1.1 ${ }^{+}$NK cells, or lymphocytes (data not shown). Pulmonary PMN endocytosed ANP in a bimodal manner, with one subset showing highly efficient uptake (ANPhigh), and the other subset demonstrating minimal to no uptake (ANPlow) (Figure 1A). Bacterial endotoxins amplify the neutrophil activation in septicemic mice, leading to increased PMN sequestration in lungs where PMN release pro-inflammatory mediators and further enhance the recruitment of immune cells (16). Using cecal ligation and puncture (CLP), a reproducible and clinically relevant mouse model of polymicrobial infection that causes ALI, we found that in naïve control mice after 2 sequential i.v. injections of ANP only $\sim 4 \%$ of lung PMN endocytosed ANP as evidenced by ANP-specific fluorescence (Figure 1B). At 6h after a sham operation, laparotomy plus cecal ligation without puncture of the cecum, and 2 sequential i.v. injections of ANP, ANPhigh 
PMN increased to only $\sim 11 \%$ (Figure 1B). Induction of severe polymicrobial sepsis by CLP,

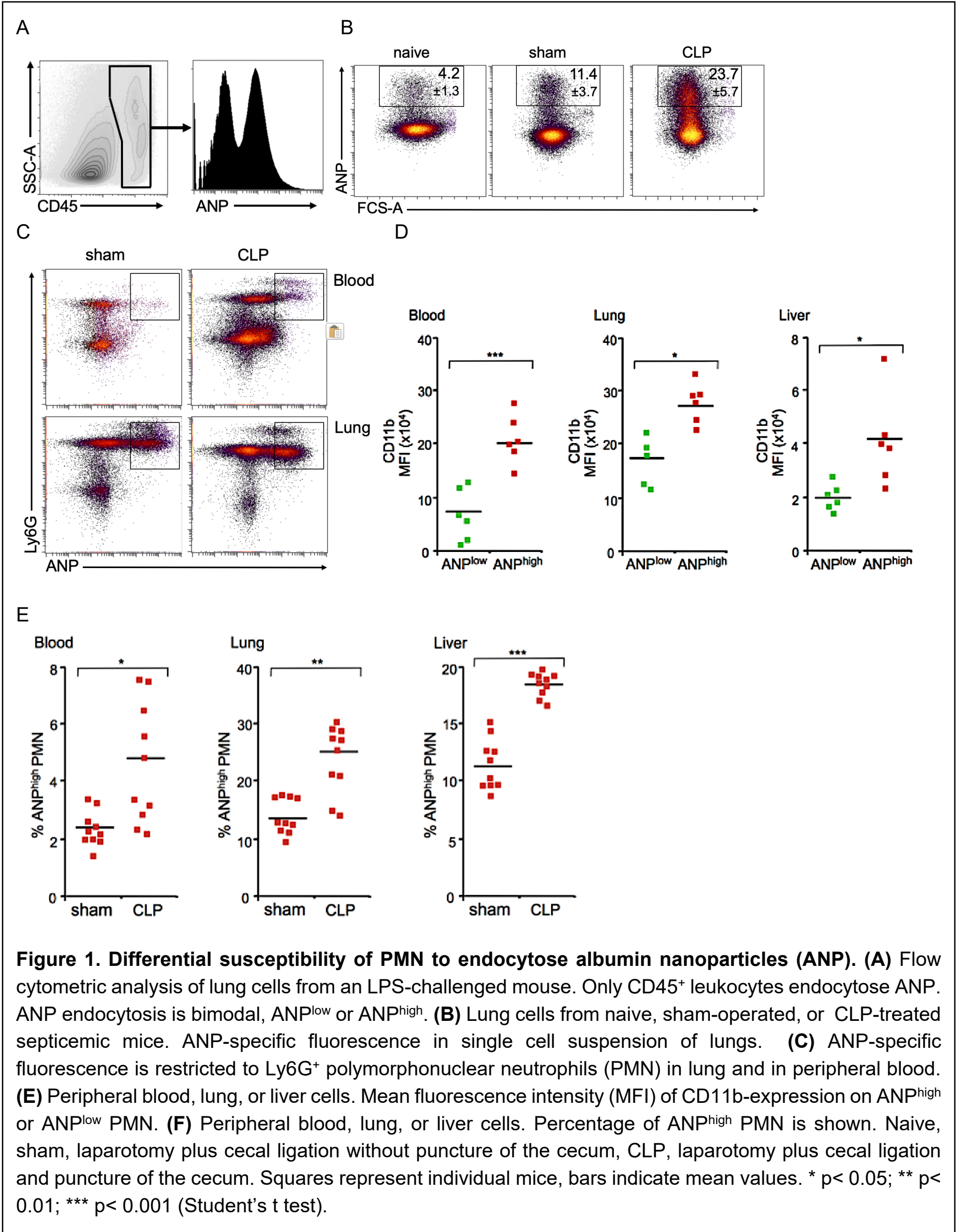


however, increased the frequency of ANPhigh lung cells 6 -fold over baseline conditions to $\sim 24 \%$ (Figure 1B). We consistently found that CD11b expression levels on PMN in peripheral blood, lung, and liver, were greater on ANPhigh PMN than on ANPlow PMN (Figure 1E), and lung ANPhigh PMN showed the highest CD11b expression (Figure 1E), indicating a higher level of inflammatory activation of the ANPhigh PMN subset. Moreover, in septicemic mice, the percentages of ANPhigh PMN was significantly greater than in sham controls in blood, lung, and liver (Figure 1F), consistent with an increased pro-inflammatory state as well as increased adhesiveness of the ANPhigh PMN subset. This heterogeneity in CD11b activation on PMN suggested that susceptibility to ANPendocytosis delineated distinct subsets of pulmonary PMN.

ANPhigh PMN have a distinct transcriptomic profile. To define the differences between the PMN subsets, we next analyzed whether ANP ${ }^{\text {high }}$ PMN had a transcriptomic profile different from ANPlow PMN. We performed an unbiased analysis of lung PMN transcriptomic profiles using RNA-Seq. We challenged mice with i.p. injections of LPS or saline and administered ANP i.v. 5h later. At $1 \mathrm{~h}$ after ANP injection, we euthanized mice and harvested PMN from single cell suspension of their lungs and sorted the Ly6G+ PMN by flow cytometry according to their ANP uptake into ANPlow and ANPhigh PMN. Immediately after sorting, we prepared PMN mRNA for RNA-Seq analysis. We generated a heat map and dendrogram (Figure 2A) to represent the normalized PMN gene expression data. We found that the biological replicates clustered into 4 groups with distinct transcriptomic profiles; i.e., the mRNA profiles defined PMN from LPS-challenged or saline-injected mice, and were distinct in ANP ${ }^{\text {low }}$ and ANPhigh PMN (Figure 2A). Using MetaCore Pathway analysis to identify pathways that were different between ANPhigh PMN and ANPlow PMN, we found that the pathways regulating immune response and immune cell migration were significantly overrepresented in the ANPhigh PMN (Supplemental Table). Pathways containing chemokine receptors were significantly enriched in ANPhigh PMN, consistent with the concept that PMN heterogeneity is a function of differential PMN trafficking into tissue presumably facilitated by different 
chemoreceptor expression. We also found that chemokine receptors were over-represented 6.5-

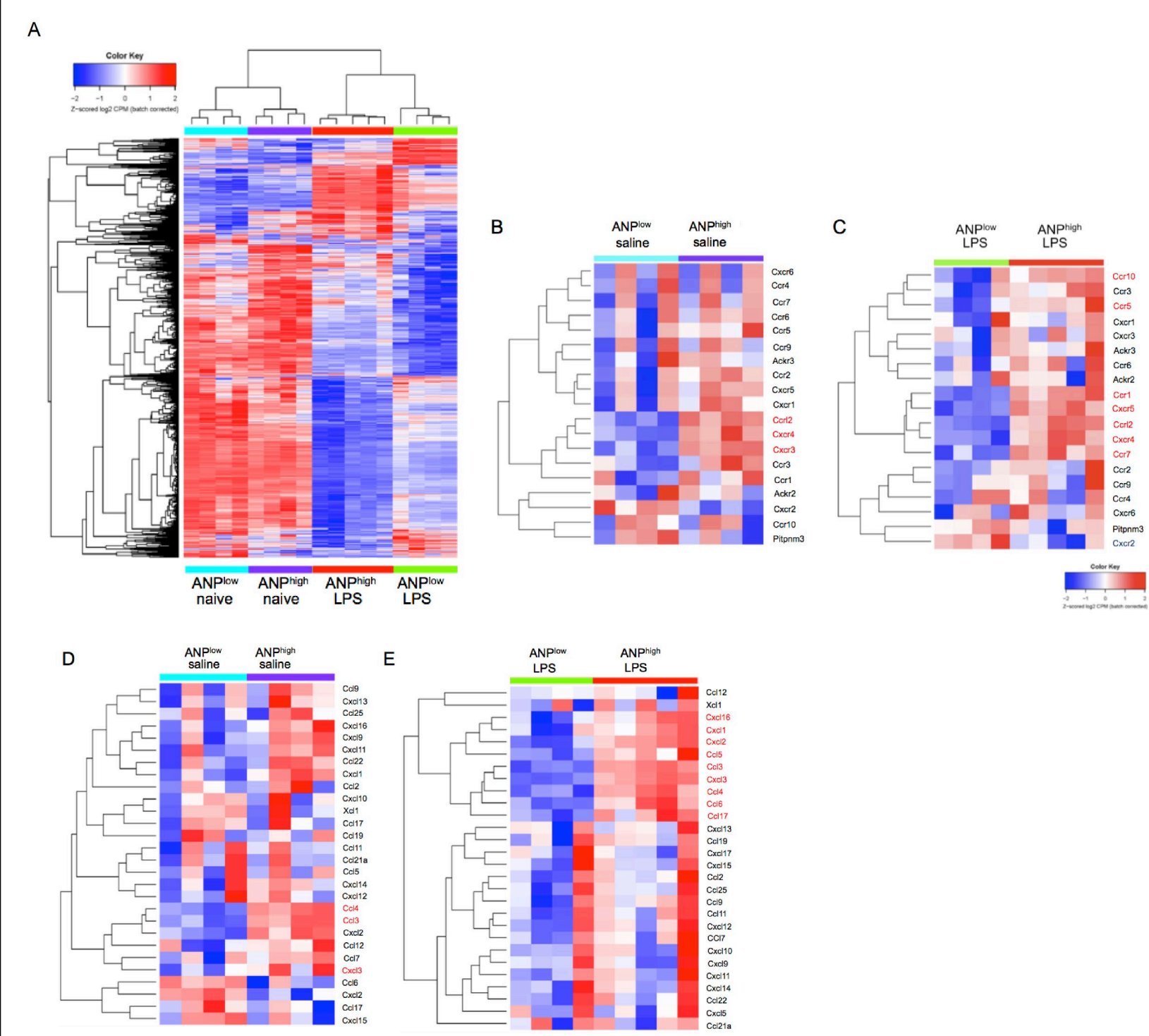

Figure 2 Lung PMN heterogeneity. A-E, Transcriptomic profile of lung Ly6G ${ }^{+}$PMN showing high and low ANP-uptake (ANP ${ }^{\text {high }}$ vs. ANPlow). (A) Dendrogram and heat map showing normalized gene expression data of biological replicate samples derived from lung PMN of saline injected control mice, ANPlow (blue), ANPhigh (purple), or of LPS-challenged mice, ANPhigh (red), ANPlow (green). (B-E) Heatmaps showing chemokine receptors and chemokines that demonstrate significantly higher expression levels in ANPhigh PMN, using an FDR (False Discovery Rate) threshold of 0.05. Chemokine receptor expression in lung PMN from (B), saline injected mice, or (C) LPS-challenged mice, or chemokine expression in lung PMN from (D) saline injected mice or (E) LPS-challenged mice. Color key, higher expression values are shown in red, lower expression values in blue. Mice were challenged for $6 \mathrm{~h}$ with one i.p. injection of LPS $(12 \mathrm{mg} / \mathrm{kg}$ ) or saline; $5 \mathrm{~h}$ after challenge, mice were injected, i.p., with one dose of fluorochrome-labeled ANP. $1 \mathrm{~h}$ later, mice were euthanized and $\mathrm{Ly}_{6} \mathrm{G}^{+} \mathrm{PMN}$ from lungs were sorted according to their ANP-uptake and their mRNA was processed for RNA-Seq. Representative data from 3 independent experiments.

fold ( $p=0.01$, Fisher's Exact test) in ANPhigh PMN derived from LPS-challenged mice and 4-fold in ANPhigh PMN of naïve mice ( $p=0.0005$, Fisher's Exact test). Moreover, chemokines were over- 
represented 3.9-fold ( $p=0.04$, Fisher's Exact test) in ANPhigh PMN of LPS challenged mice and 3fold in ANPhigh PMN of naïve mice ( $p=0.0013$, Fisher's Exact test).

To identify the chemokine receptors for each PMN subset, we generated separate heatmaps for chemokine receptors, plotting all genes with $\mathrm{CPM}>0.25$ (10 reads at sequencing depth of $40 \mathrm{M}$ reads) regardless of differential expression levels. In naïve mice, ANPhigh PMN showed relative over-expression of chemokine receptors Cxcr3, Cxcr4, and Ccrl2 (Figure 2B). In LPSchallenged mice, ANPhigh PMN showed relative over-expression of chemokine receptors Ccr1, Ccr5, Ccr7, Ccr10, Ccrl2, Cxcr4 and Cxcr5 (Figure 2C). We next assessed the expression of chemokines in ANPhigh PMN and ANPlow PMN. In saline injected control mice, ANPhigh PMN were significantly enriched for the expression of the chemokines $\mathrm{Ccl} 3, \mathrm{Ccl} 4$, and $\mathrm{Cxcl} 3$ (Figure 2D). In LPS-challenged mice, ANPhigh PMN demonstrated relative over-expression of the chemokines Ccl3, Ccl4, Ccl5, Ccl6, Ccl17, Cxcl1, Cxcl2, Cxcl3, Cxcl16 (Figure 2E). Of note, mice were only exposed to ANP for the last hour of the 6h LPS-challenge, and the differences in gene expression between ANPhigh PMN and ANPlow PMN in LPS challenged mice were far greater than those in the naïve mice, indicating that the ANP uptake itself likely did not affect the gene expression profiles.

These RNA-Seq data unequivocally demonstrated the existence of lung PMN subsets with a distinct response to the inflammatory stimulus LPS. Based on our RNA-Seq data and MetaCore Pathway analysis, we selected a group of chemokine receptors and cytokines to determine the kinetics of their expression after LPS-stimulation. We performed this independent validation by quantitative PCR (qPCR) and flow cytometry. We found that mRNA expression of the chemokine receptor Ccr1 was significantly greater in ANPigh PMN than in ANPlow PMN at 3h, 6h, and $12 \mathrm{~h}$ after LPS challenge (Figure 3A). Importantly, we found that CCR1 receptor cell surface expression, consistent with the mRNA data, was significantly greater on lung ANPhigh PMN than in ANPlow PMN before and $3 \mathrm{~h}, 6 \mathrm{~h}$, and $12 \mathrm{~h}$ after LPS stimulation (Figure 3B). CXCR2 expression was reduced at 6h after LPS-stimulation compared to $3 \mathrm{~h}$ stimulation, CXCR4 receptor cell surface expression increased at $3 \mathrm{~h}$ after LPS-stimulation and was greater in ANPhigh than in ANPlow PMN, and 
decreased to expression levela of unstimulated PMN thereafter (Figure 3B). These data

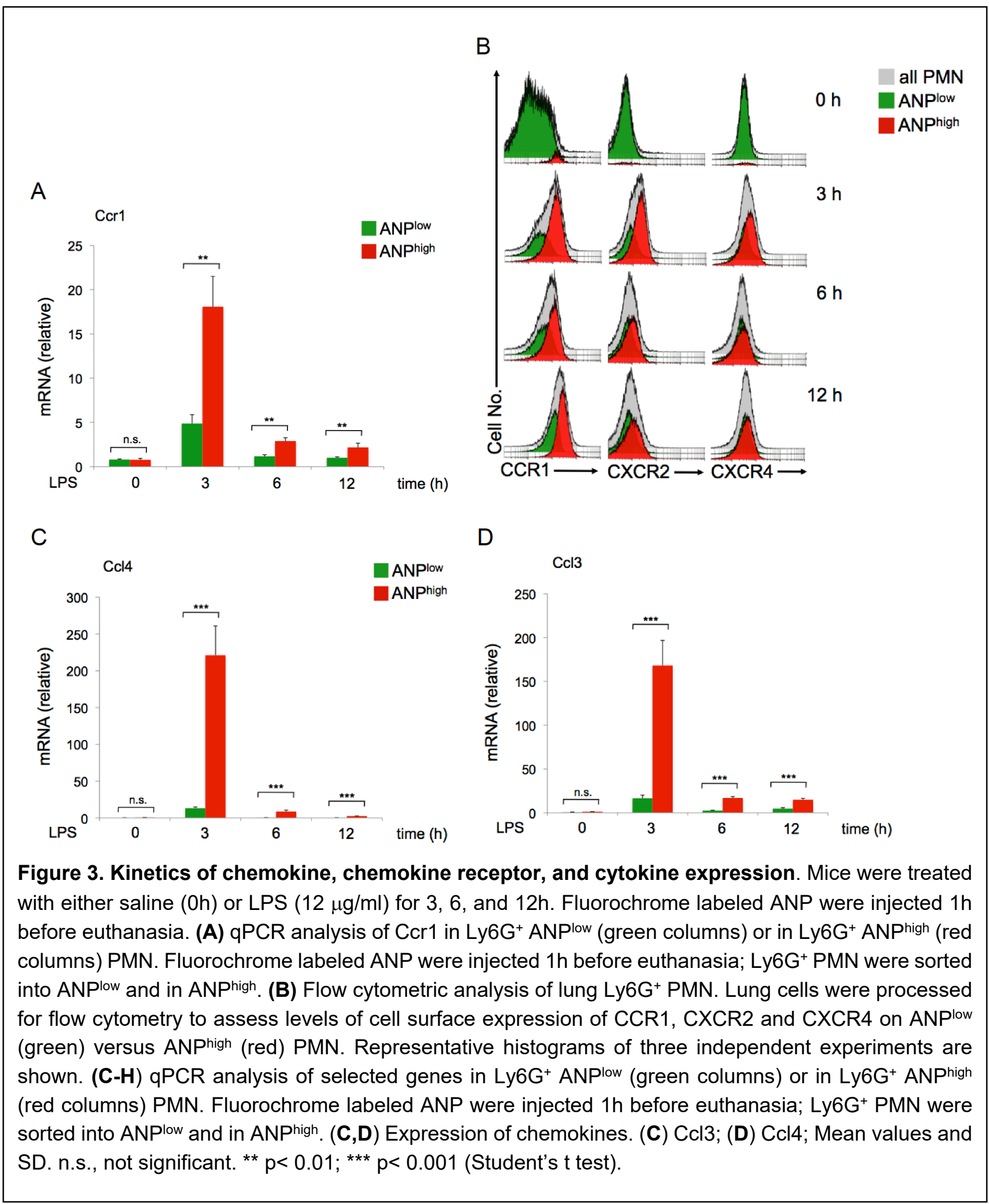

demonstrate that the observed mRNA expression heterogeneity translated into cell surface protein expression heterogeneity. 
The mRNA levels of the chemokines Ccl4, Ccl3, Cxcl2, Cxcl3 (Figure 3C-F) were

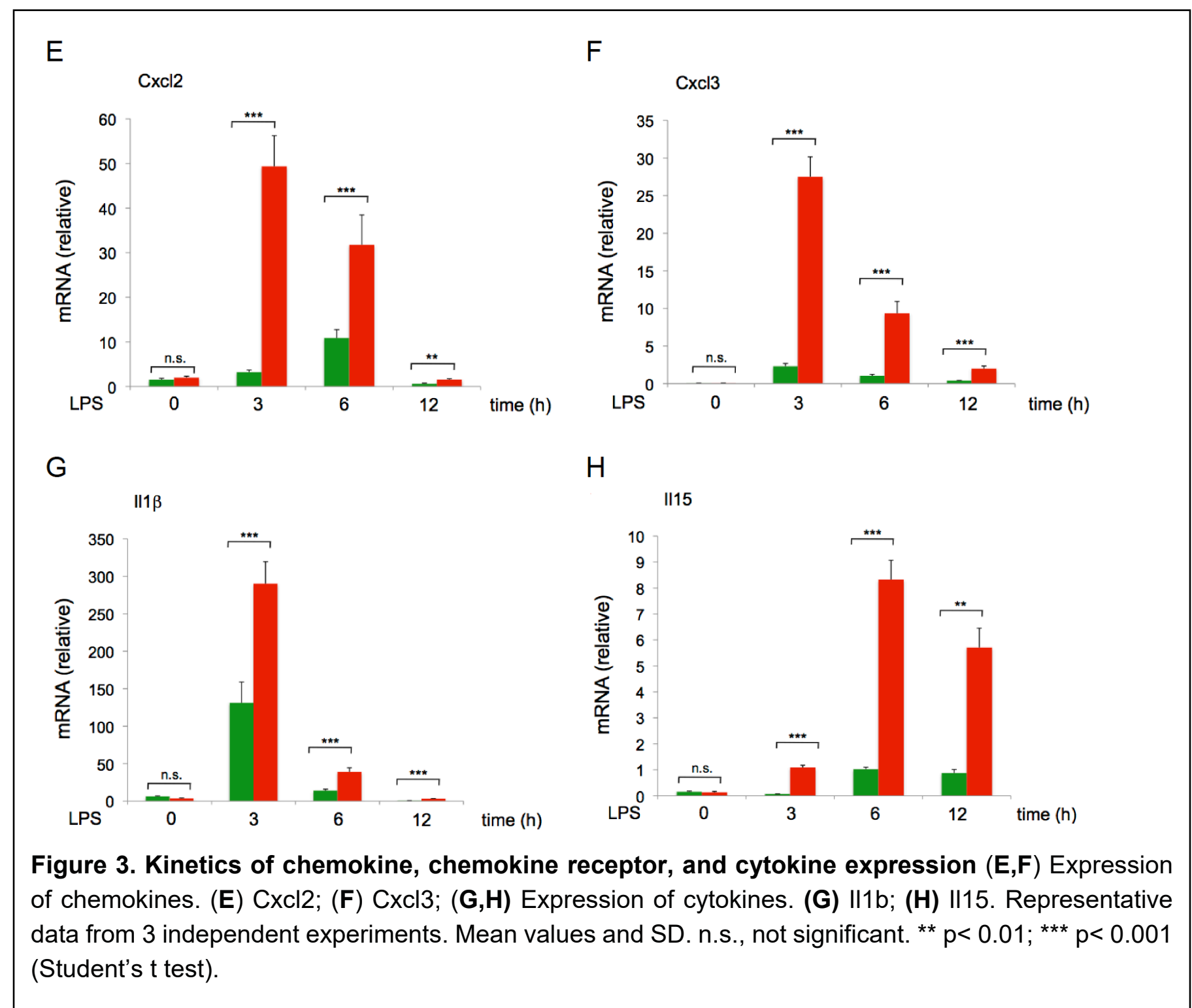

significantly greater in ANPhigh PMN than in ANPlow PMN 3h, 6h, and $12 \mathrm{~h}$ after in vivo LPS challenge. Ccl4 (Figure 3C) and Ccl3 (Figure 3D) expression, in particular, was vastly greater in ANPhigh than in ANPlow PMN, suggesting that ANPhigh PMN are specialized cells of inflammation, which recruit and activate additional PMN. In addition, heterodimers of CCL3 and CCL4 are known to attract monocytes/macrophages (17). The cytokine IL-1 $\beta$ is essential for antibacterial function and expression of IL1 $\beta$ was induced $\sim 21$-fold in ANPlow PMN 3h after LPS challenge compared to ANPlow PMN from saline injected control mice (Figure 3G); in ANPhigh PMN, IL1 $\beta$ was induced $~ 78-$ fold over ANPhigh PMN from saline injected control mice (Figure 3H). Expression of the pleiotropic cytokine IL-15 expression was significantly greater in the ANPhigh than in the ANPlow PMN in lungs 
3h, 6h, and $12 \mathrm{~h}$ after LPS challenge (Figure $3 \mathrm{H}$ ). These data demonstrate that pulmonary ANPhigh PMN can markedly amplify the inflammatory response.

ANPhigh PMN transfer inflammation to lungs of naive mice. We next determined whether adoptively transferring ANP ${ }^{\text {high }}$ PMN from donors into syngeneic recipient mice would induce inflammation in these mice. Donor BALB/c mice were challenged with a lethal dose of LPS $[30 \mathrm{mg} / \mathrm{kg}]$ and injected with two doses of ANP labeled with the stable fluorochrome AF647 at $1 \mathrm{~h}$ and $2 \mathrm{~h}$ after LPS challenge (Figure 4A). At $3 \mathrm{~h}$ after LPS challenge, donor mice were euthanized and lung single cell suspensions were prepared for flow cytometric sorting into ANPhigh and ANPlow neutrophils (Figure 4B). Syngeneic recipient mice were injected i.v. with $8 \times 10^{5}$ pulmonary ANPhigh PMN or, as controls, with an equal number of pulmonary ANPlow PMN from the same donors (three donors per recipient mouse were required to achieve the necessary cell number). At $2 \mathrm{~h}$ prior to transfer of donor cells, recipient mice were treated with a sublethal dose of LPS [1 $1 \mathrm{mg} / \mathrm{kg}$ ] to activate their endothelium, a prerequisite for initiating neutrophilic lung inflammation (18). At $20 \mathrm{~h}$ after the adoptive transfer, we assessed lung inflammation in recipient mice (Figure 4A). We found $\mathrm{ANP}^{+} \mathrm{Ly}_{6 \mathrm{G}} \mathrm{G}^{+} \mathrm{PMN}$ in lungs of recipient mice, confirming successful transfer of donor cells to recipient mice and their homing to the lung (Figure $4 C$ ).

Transfer of donor ANPhigh PMN significantly increased lung inflammation in the recipient mice when compared to mice that received ANPlow cells (Figure 4C). Moreover, after transfer of ANPhigh PMN, lung Ly6G+ PMN produced more ROS when compared to controls receiving ANPlow PMN (Figure 3D). Because ROS induce tissue inflammation (12, 19), and ANPhigh cells are carriers of large amounts of mRNA for inflammatory cytokines and chemokines (Figure 3), we measured the inflammatory mediators $\mathrm{IL}-1 \beta$ and $C X C L 2$ in lung tissue extracts. IL-1 $\beta$, released during activation of NLRP3 inflammasome, mediates tissue injury, whereas the chemokine CXCL2 amplifies the inflammatory cycle by attracting additional pro-inflammatory neutrophils (20-22). Mice 


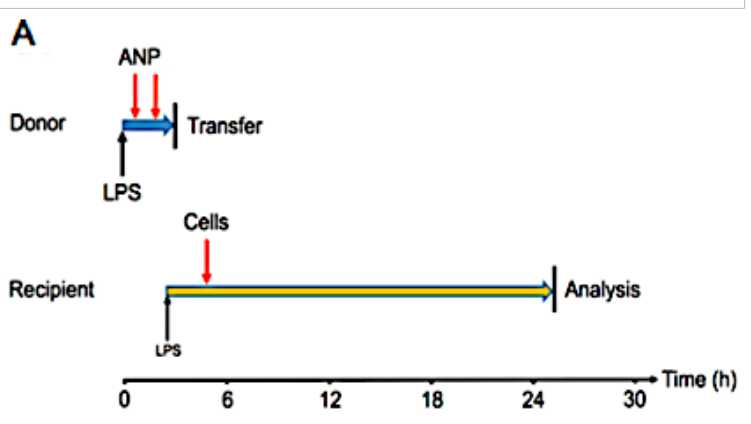

C

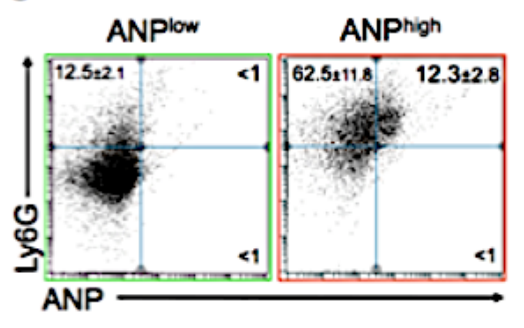

D

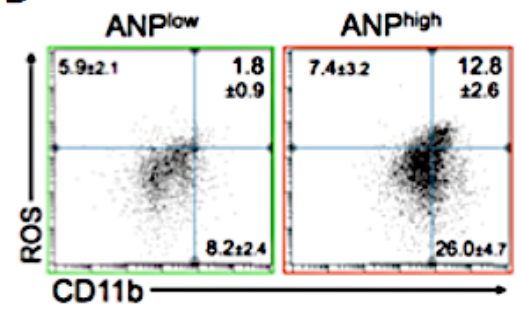

B

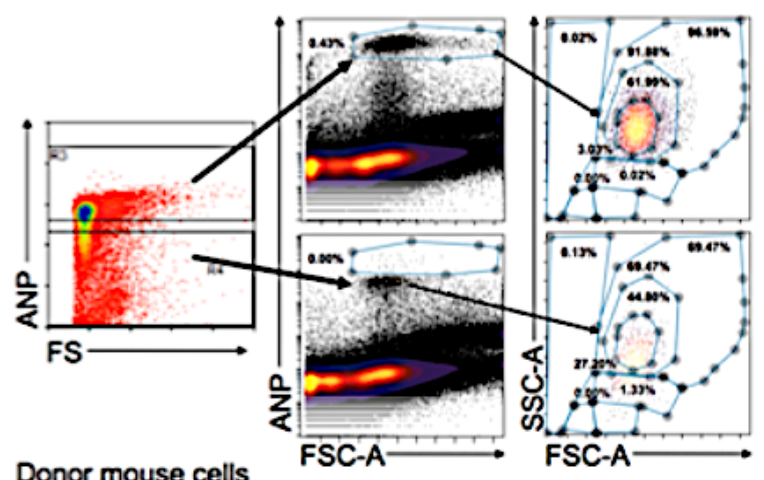

Recipient mouse cells

E

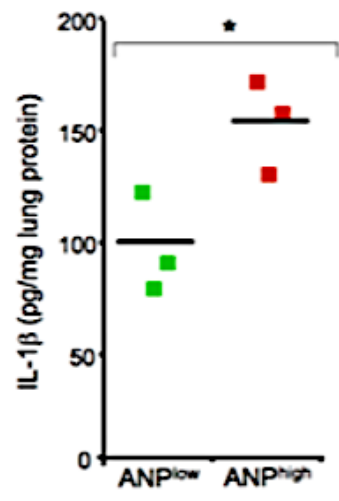

$\mathbf{F}$

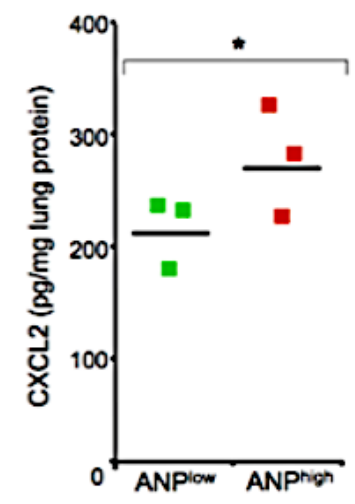

Figure 4. ANPhigh $P M N$ transfer induces inflammation in naïve lungs. (A) Donor mice were challenged with a lethal dose of LPS and injected with two doses of ANP labeled with the stable fluorochrome AF647, 1 and $2 \mathrm{~h}$ after LPS challenge. 3h after the LPS challenge, donor mice were sacrificed and lung single cell suspensions enriched for leukocytes were prepared. Syngeneic recipient mice were pretreated with low-dose LPS $2 \mathrm{~h}$ prior to adoptive transfer by intravenous injection of $8 \times 10^{5}$ ANPhigh PMN or, as controls, an equal number of ANPlow cells. 20h after the adoptive transfer recipient mice were sacrificed for analysis. (B) Flow cytometric sorting into ANPhigh and ANPlow donor lung cells and flow cytometric analysis of recipient mouse lung cells. Granulocytes were gated by SSC-A ${ }^{\text {high }}$ FSC$A^{\text {high }}$. (C) Flow cytometric analysis of lung cells from mice that have received ANPlow, green, or ANPhigh, red, donor cells. Dot blot showing the percentages of Ly6G ANP double- or single-positive PMN. Percentages of $\mathrm{Ly}_{6 \mathrm{G}} \mathrm{ANP}^{+}$cells were significantly greater in mice that received ANPhigh donor cells compared to mice that received ANPlow donor cells: $p<0.001$ (Student's t test). (D) Flow cytometric analysis of lung cells from mice that have received ANPlow, green, or ANPhigh, red, donor cells. Dot blot showing the percentages of ROS CD11b double- or single-positive PMN. Percentages of ROS ${ }^{+}$CD $11 b^{+}$ were significantly greater in mice that received ANPhigh donor cells compared to mice that received ANPlow donor cells. (E) Concentrations of the IL-1 $\beta$ in lung tissue extracts from mice that have received ANPlow or ANPhigh donor cells. (F) Concentrations of CXCL2 in lung tissue extracts from mice that have received ANPlow or ANPhigh donor cells. $p<0.01$ (Student's $t$ test). Representative data from 3 independent experiments using cohorts of at least 3 recipient and 9 donor mice are shown. 
(Figure 4F) in their lungs than recipients of ANPlow PMN. These data demonstrated the intrinsic ability of ANPhigh PMN to promote lung inflammation.

\section{Therapeutic administration of ANPhigh PMN loaded with piceatannol protects mice from}

lethal polymicrobial sepsis. Integrin signaling is a main determinant of PMN behavior in vivo.

Firm PMN adhesion on microvascular endothelium, induced by endotoxin or bacteremia, upregulates Mac-1 (a heterodimer of CD11b and $\beta_{2}$-integrin CD18), contributing to maximal activation of PMN (23). Syk activity is required for $\beta 2$-integrin-mediated neutrophil activation (24). Given our data above, we reasoned that inhibiting integrin signaling specifically in the subset of ANPhigh PMN would reduce lung inflammation in the polymicrobial sepsis model. We thus used the drug piceatannol, a Syk inhibitor $(25,26)$, that is readily incorporated into ANP due to its poor water solubility $(15,27)$, to inhibit Syk-mediated $\beta_{2}$-integrin-dependent neutrophil adhesion. We found that therapeutic administration of piceatannol loaded ANPhigh PMN protected CD1 mice from lethal polymicrobial sepsis (Figure 5A). Treatment with two i.v. injections of piceatannol incorporated into ANP (PANP), $2 \mathrm{~h}$ and $4 \mathrm{~h}$ after CLP, significantly reduced mortality of mice when compared to control groups treated with ANP without any drug after challenge with CLP (Figure 5A). Treatment using PANP reduced CLP lethality to the rate of sham-operated (laparotomy plus cecal ligation without puncture of the cecum) mice (Figure 5A). Injections of PANP alone had no effect on the survival rate compared to saline injected controls (Figure 5A). CLP challenged mice treated with ANP, without any drug, had the same mortality rate as saline-injected controls (Figure 5A), demonstrating that targeting specifically the ANPhigh subset of PMN is sufficient to prevent CLP-induced mortality. Similarly, in the absence of polymicrobial infection but after i.p. challenge with a lethal dose of the endotoxin LPS (LD80), mice treated with 2 sequential i.v. injections of PANP $1 \mathrm{~h}$ and $2 \mathrm{~h}$ after LPS challenge, showed significantly reduced mortality when compared to control mice injected with ANP alone (Figure 5B). Reduced mortality after PANP treatment was correlated with the presence of significantly fewer highly inflammatory CD11 $\mathrm{b}^{\text {high }} \mathrm{CD} 45^{\text {high }} \mathrm{PMN}$ (Figure 5C), and reduced CD11b expression on lung PMN when compared to ANP-treated controls (Figure 5D). Furthermore, while 
CD11b expression on PMN was reduced by PANP treatment in the lungs, in peripheral blood PMN

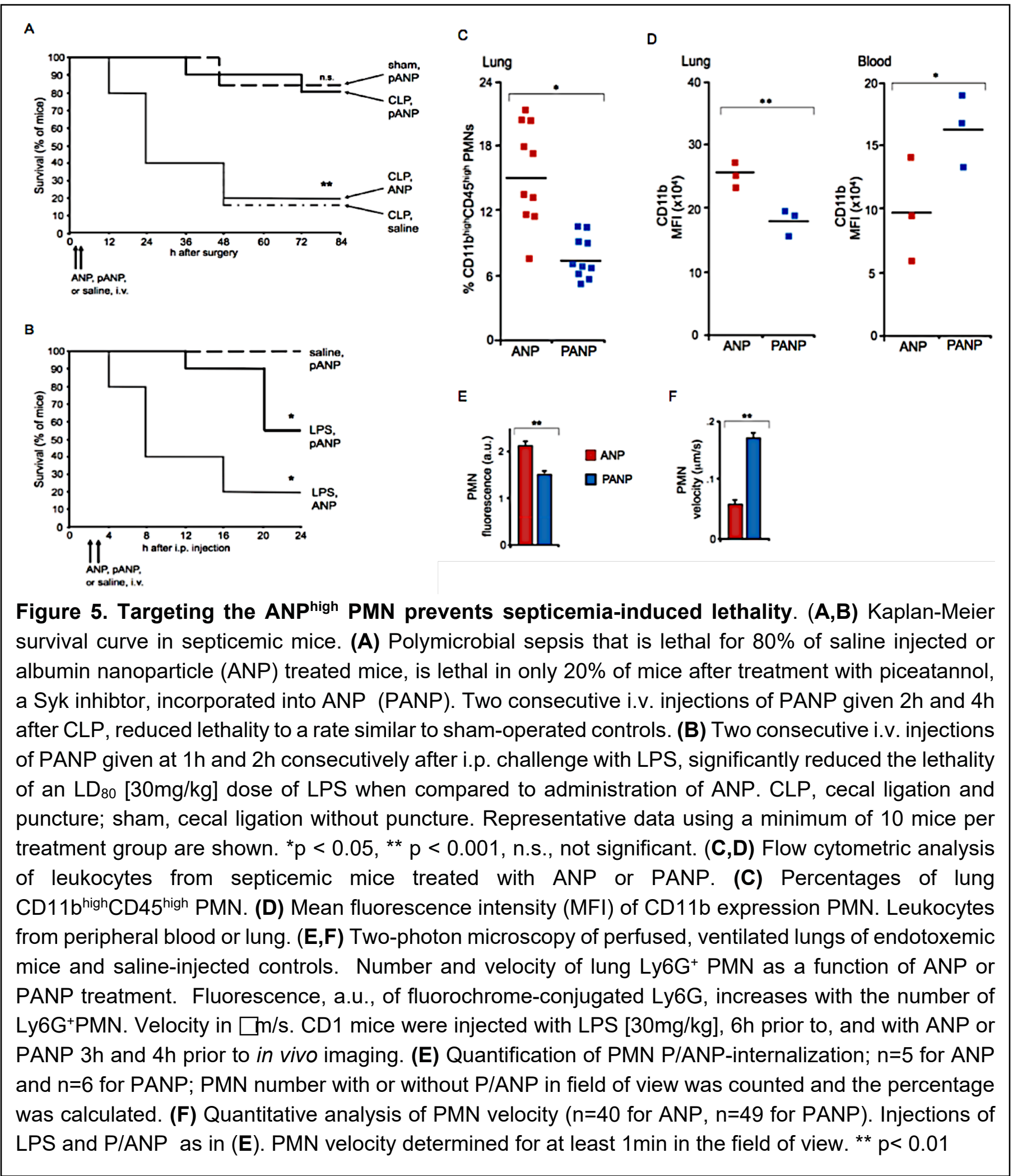

CD11b surface-expression was higher when compared to PMN from ANP-treated mice (Figure

5D). 
To test whether augmented CD11b expression on PMN in peripheral blood was a consequence

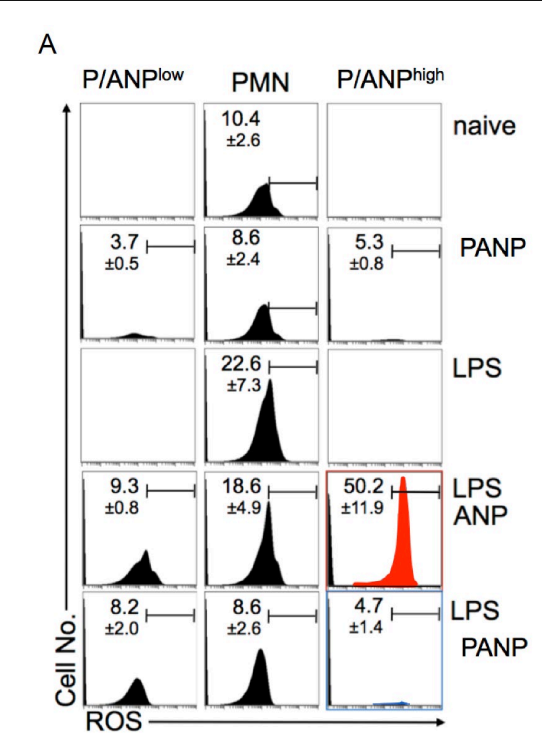

B
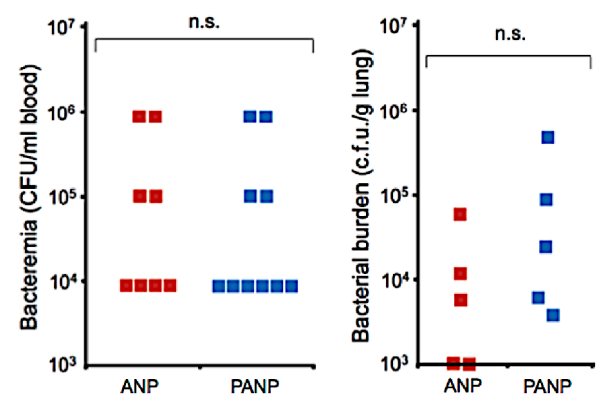
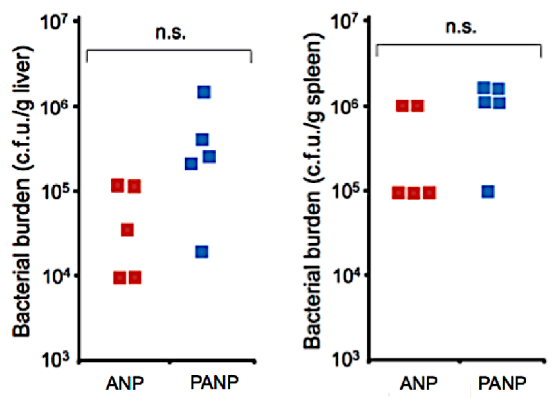

C
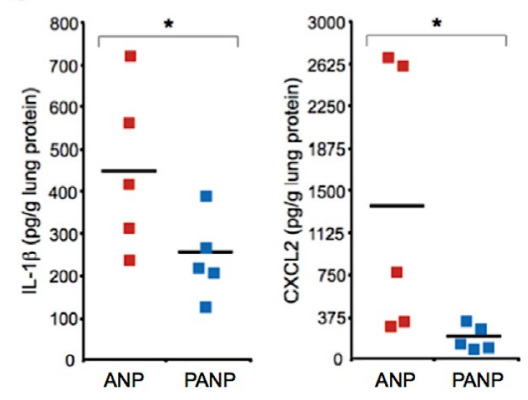

Figure 6. Targeting ANP ${ }^{\text {high }}$ PMN improves tolerance of polymicrobial infection. (A) Flow cytometric analysis of intracellular ROS in pulmonary PMN. Mice were treated with 2 consecutive i.v. injections of PANP or ANP $1 \mathrm{~h}$ and $2 \mathrm{~h}$ after i.p. challenge with LPS and ROS was measured $6 \mathrm{~h}$ after challenge. Histograms representing ROS in all Ly6G ${ }^{+}$PMN, ANPhigh or PANPhigh (P/ANPhigh). ROS production was measured by DHR-123 After LPS challenge, ANPhigh PMN produce inordinate amounts of ROS (histogram shown in red), that are significantly reduced by piceatannol (PANP) treatment (histogram shown in blue). Representative data from a minimum of 3 mice per treatment group are shown. (B) Bacterial load (CFUs) in peripheral blood, lungs, livers, or spleens of mice post-CLP. Two consecutive i.v. injections of PANP given $2 \mathrm{~h}$ and $4 \mathrm{~h}$ after CLP did not increase bacterial burden $18 \mathrm{~h}$ after surgery compared to ANP treated controls. (C) IL-1 $\beta$, CXCL2 in lung protein lysate of mice $18 \mathrm{~h}$ after CLP. Two i.v. injections of PANP or ANP were given $2 \mathrm{~h}$ and $4 \mathrm{~h}$ after CLP. Squares represent values from individual mice and lines indicate mean values. ${ }^{*} \mathrm{p}<0.05$.

of PANP-induced PMN trafficking from the lung to the peripheral blood, we used two-photon microscopy to visualize PMN trafficking in the lung in vivo (28). We determined the number of Ly6G ${ }^{+}$ PMN in microvasculature and velocity of their migration through the microvasculature in lungs (Video, Figure 5E). In LPS challenged CD1 mice, the number of PMN increased, as measured by PMN-specific fluorescence (Video). Treatment of PMN with PANP, however, significantly increased the velocity of $\mathrm{Ly}_{6 \mathrm{G}}+\mathrm{PMN}$ in the lung microvasculature and reduced the number of $\mathrm{Ly}_{6 \mathrm{G}} \mathrm{PMN}^{+}$as 
compared to ANP treated controls (Movie, Figure 5E,F). Cell targeted treatment of ANPhigh PMN by inhibiting $\beta_{2}$-integrin signaling, and accelerated the transit of PMN through lungs, and thus reduced exposure time of lung tissue to noxious PMN-derived mediators.

Therapeutic targeting ANPhigh PMN improves tolerance to polymicrobial infection. Excessive ROS production is a potent mediator of tissue damage $(12,19)$. We found that ANPhigh cells were characterized by high ROS production (Figure 4D). Syk, whose enzymatic activity is the cellular target of piceatannol (25), is required for integrin-mediated neutrophilic superoxide production (24). We measured ROS production by bone marrow Ly6G+ PMN in vitro (Supplemental Figure 2). Bone marrow PMN responded to stimulation with the bacterial peptide fMLP with ROS production (Supplemental Figure 2). PMN with higher uptake of PANP showed greater reduction in ROS production (Supplemental Figure 2). Moreover, the delivery of piceatannol via PANP increased drug efficacy by orders of magnitude when compared to free drug because of its incorporation in the toxic PMN subset (Supplemental Figure 2). We therefore examined whether PANP treatment reduced superoxide production by lung PMN of endotoxemic mice. We challenged mice with a lethal dose of LPS and analyzed the production of ROS by the lung Ly6G+ PMN ex vivo. We found that ANPhigh PMN had significantly higher intracellular ROS levels than ANPlow PMN (Figure 6A). PANP treatment, however, almost completely blocked ROS production in these cells (Figure 6A). These data demonstrated that ANPhigh PMN are largely responsible for ROS production by lung inflammatory cell in endotoxemia because targeted treatment via PANP markedly reduced ROS production.

Mice doubly deficient for NADPH oxidase and iNOS (gp91phox ${ }^{-/-}$nos $2^{-/-}$) develop spontaneous infections (29). ROS production and complementary NO production by PMN are essential to control host microbial diversity and microbial infection (29), and functional lung PMN are essential for the task of clearing bloodstream bacteria because resident macrophages in liver and spleen alone are insufficient $(30,31)$. We therefore determined the effects of PANP treatment on the bacterial burden of CD1 mice in the CLP model of polymicrobial infection. We found no exacerbation or amelioration 
of the bacterial burden as a result of PANP treatment when compared to ANP treatment (Figure $6 B)$, suggesting that selective inhibition of integrin signaling in the ANPhigh PMN subset did not compromise bacterial elimination. Two consecutive i.v. injections of PANP, given $2 \mathrm{~h}$ and $4 \mathrm{~h}$ after CLP, did not increase bacteremia when compared to ANP injected controls (Figure 6B). The bacterial burden of lungs, livers, and spleens of bacteremic mice was similar between PANPtreated mice and ANP-treated controls (Figure 6B). PMN-dependent antimicrobial function was fully preserved after PANP treatment, suggesting that antimicrobial functions, ingestion and elimination of bacteria are mainly performed by ANPlow PMN (Supplemental Figure 3).

Because PANP treatment did not weaken anti-microbial resistance, we analyzed parameters of tissue inflammation and damage We measured crucial inflammatory mediators, IL-1 $\beta$, and CXCL2. In lung tissue extracts of mice subjected to CLP. We found a substantial reduction in the concentration of IL-1 $\beta$ and CXCL2 after PANP treatment when compared to ANP treated controls (Figure 6C). We next measured nitrotyrosine formation in lungs and livers of septicemic mice. In the experimental mice as well as in septicemic patients, activated lung myeloid cells, inflammatory or resident, and epithelial type II cells, release both $\mathrm{NO}$ and superoxide which react to form peroxynitrite, a potent oxidant causing tissue damage (32). Peroxynitrite $\left(\mathrm{ONOO}^{-}\right)$, but not NO or superoxide alone, nitrates tyrosine residues (32). We observed that nitrotyrosine-specific staining in inflammatory and parenchymal cells was significantly reduced in lungs and livers of mice treated with PANP when compared to ANP-treated controls (Figure 6D,E). These data suggest that antimicrobial function and tissue damaging function are performed by distinct subsets of PMN.

We next determined the effect of PANP treatment on pulmonary edema which is a characteristic feature of inflammatory lung injury. A marked increase in lung wet-to-dry weight ratio is indicative of breakdown of the alveolar capillary barriers, the hallmark of ALI. Pneumonia is the most common cause of ALI in patients (33) and also the most common cause of sepsis (8). In the model of pneumonia induced by i.t. instillation of live $P$. aeruginosa bacteria, PANP treatment significantly reduced pulmonary edema when compared to treatment with the control ANP (Figure 6F). 


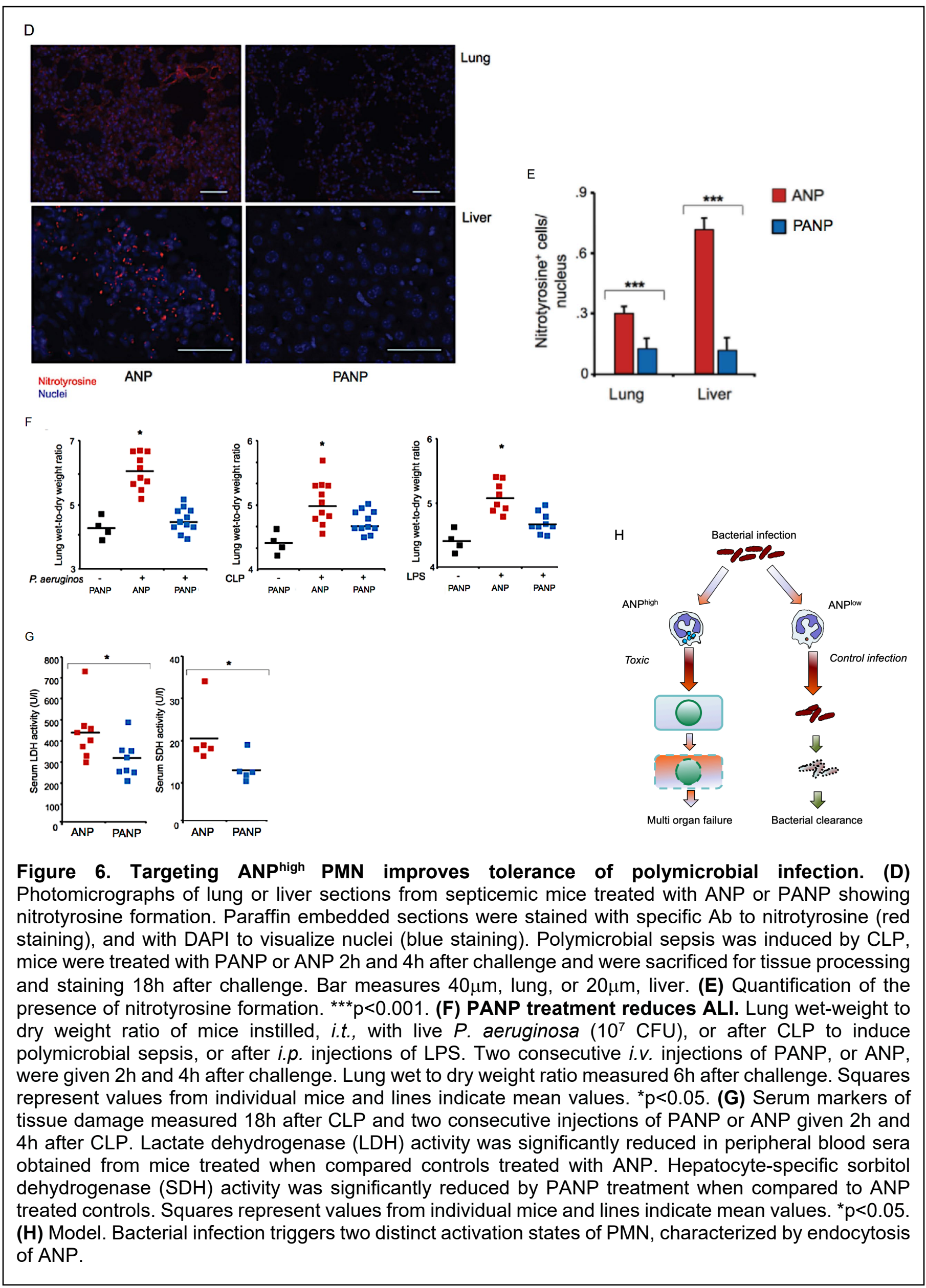


Furthermore, treatment with PANP significantly reduced pulmonary edema in endotoxemic or septicemic mice when compared to lungs from ANP treated controls (Figure 6F). A reduction of tissue damage, because of reduced lung inflammation, could be the proximate cause of reduced inflammatory lung injury after treatment. Measuring a markers of overall cell damage, lactic dehydrogenase (LDH) (34), revealed that the polymicrobial sepsis-induced increased serum activity of LDH was significantly reduced by PANP treatment when compared to ANP treated controls (Figure 6G). In addition, hepatocyte-specific sorbitol dehydrogenase (SDH) activity, a marker of hepatocyte damage (35), was also significantly reduced by PANP treatment of septicemic mice (Figure 6G). Endocytosis of ANP delineates two distinct subsets of PMN. ANPhigh PMN cause tissue damage whereas ANPlow PMN control microbial infection (Figure 6H).

\section{Discussion}

Targeting neutrophilic inflammation that is pathogenic in ALI remains an important unmet clinical need. Our observation that neutrophils primed by bacterial infections or bacterial derived products exhibit heterogeneity in their capacity to endocytose ANP lead to the discovery of two distinct neutrophilic subsets, one that causes inflammatory injury and one that controls microbial infection. Functional and phenotypic PMN heterogeneity (36-40) led us to test the hypothesis that immunopathology and severe tissue inflammation of endotoxemia and septicemia can be treated by targeting a distinct neutrophilic subset. Increased expression of chemokines and chemokine receptors in ANPhigh PMN was consistent with their role in promoting tissue inflammation. Several of the chemokines such as CCL3 and CCL4 or CXCL2 and CXCL3 are members of the macrophage inflammatory protein family and are typically thought to be released by macrophages to increase the influx of pro-inflammatory cells such as neutrophils (41). Our data suggest that a subset of neutrophils might be a substantial source of these inflammatory proteins in models of ALI. All cells need to express genes that are required for their intrinsic functions, whereas production of secreted factors can be delegated to subsets (42). Our results indicate that a specific subset of 
phenotypic and functionally distinct neutrophils is responsible for lethality in experimental polymicrobial sepsis. ANPhigh PMN were characterized by higher expression of the chemokine receptors for the ligands released following LPS activation such as CCR1 and CCR5 (the receptors for CCL3) which could point to a possible positive feedback loop in which inflammatory ANPhigh PMN attract additional inflammatory PMN, and thus actively promote a vicious cycle of hyperinflammation and tissue injury (43). Given their phenotypic and functional profile, ANPhigh PMN might play a pathogenic role in COVID-19, the disease caused by coronavirus SARS-Cov-2 (44). The main cause of COVID-19-mortality is acute respiratory failure (45). In patients with severe COVID-19, activated neutrophils, recruited to the pulmonary microvasculature, produce histotoxic mediators including ROS (46). Activation of neutrophils might contribute to cytokine release syndrome ("cytokine storm") that characterizes severe COVID-19 disease (47). Therapy targeting ANPhigh PMN might prevent a patient's hyperinflammatory response to SARS-Cov-2 without weakening the antiviral response.

It has been shown that the incorporation of denatured albumin beads depends on Mac-1 expression (48). ANP-incorporation, by contrast, is Mac-1-independent (15) suggesting a distinct molecular mechanism of ANP-endocytosis. "Aged neutrophils", were first described in vitro as functionally deficient (49) and have been subsequently shown to promote disease in vivo in models of sickle-cell disease or endotoxin-induced septic shock (50). While "Aged neutrophils" home to the bone marrow under steady-state conditions ANPhigh PMN do not home to the bone marrow under steady-state conditions and markers of aged peripheral blood neutrophils, CXCR4, CXCL2, CD62L, and TLR4, do not distinguish ANPhigh from ANPlow PMN under steady-state or inflammatory conditions in the lung (Figure 2). These findings thus show that the previously described subset of aged neutrophils is distinct from the ANP ${ }^{\text {high }}$ PMN subset we identified.

Administration of ANP carrying piceatannol, a Syk inhibitor, dramatically improved survival in polymicrobial sepsis but, critically, did not increase the host's bacterial burden. Syk function is required for the essential antibacterial functions of neutrophils (51). We found that ANPlow PMN are 
more efficient in ingestion and elimination of $E$. coli bacteria in vitro than ANPhigh PMN and inhibition of Syk in ANPhigh PMN does not impair control of polymicrobial infection in vivo. By therapeutically leveraging the preferential ANP uptake of the inflammatory PMN subset, we succeeded in limiting immunopathology caused by polymicrobial infection. Pathogens adapt to host resistance mechanisms, but not host tolerance mechanisms (52). It is conceivable that an ANP-based approach of targeting toxic subset of neutrophils, by improving host tolerance, might assist the host in combating antibiotic-resistant microbial infections (53). ANP could also be used to deliver compounds other than piceatannol or to specifically deliver siRNAs or microRNAs. Furthermore, ANP-based therapy might be useful in other forms of neutrophilic injury; e.g., ischemia reperfusion injury of the myocardium or the kidney (54).

The ability to tolerate pathogens in experimental polymicrobial sepsis was greatly strengthened by targeting ANPhigh PMN with a drug that accelerates the velocity of pulmonary PMN and abrogates their ROS production. PANP did not target $\beta_{2}$-integrins directly (15) but mitigated downstream $\beta_{2}$-integrin signaling, and are thus more likely to be effective when $\beta_{2}$-integrin are already engaged; i.e., in the lung microvasculature of septic patients (55). Further potential improvement of ANP-based therapies over the current standard treatments of septic patients (56) lies in the precision targeting of the relevant pathogenic subset of neutrophils. Earlier efforts to neutralize reactive oxygen species, to use antibodies against key inflammatory cytokines such as TNF- $\alpha$, IL-1 $\beta$, or to inhibit the endotoxin LPS $(8,57-59)$ have failed to reduce mortality associated with ALI/ARDS possibly because they did not discriminate between PMN subsets and may have compromised both host defense (resistance) and tissue repair (tolerance) (33). Compared with the therapeutic administration of exogenous cells, generated from donors or from the patients themselves, for example, mesenchymal stromal/stem cells (MSCs) (60), ANP-based therapy has the advantage of targeting the host's endogenous cells dependent on their pathogenic activation.

One limitation of our approach is that we cannot distinguish whether the specification into ANPhigh PMN occurs in the bone marrow prior to egress of PMN into circulation or whether it occurs 
in the tissue itself. It is also possible that the ANPhigh state characterized by upregulation of chemokine receptors and chemokine ligands is reversible and that PMN can transition between these states, in response to environmental cues even during the short life-span of neutrophils (61).

The present data support the concept that the generation of heterogeneous PMN subpopulations evolved as a host defense mechanism to avoid an indiscriminate response by all PMN to septicemia (42). A heterogeneous response of PMN to bacterial challenge below the threshold of septicemia may be sufficient to contain the infection and avoid immunopathology by striking a balance between an inflammation-amplifying PMN subset and a pathogen-eliminating PMN subset. However, excessive systemic infection may overwhelm this adaptive mechanism and shift the balance towards excessive activation of the pro-inflammatory PMN subpopulation that via the positive feedback loop of attracting even more PMN via chemokines causes tissue damage. Inhibiting Syk-dependent functions of this subset of inflammatory PMN as described would reduce damage, increase tolerance, and have no detrimental effect on the anti-microbial function of the host. The data demonstrate that sepsis represents an excessive, inappropriate activation of a subset of PMN and not an all-out indiscriminate response by PMN to septicemia. The separation of host defense function from tissue inflammatory function is reflected in the heterogeneous ability of PMN to incorporate ANP. Co-option of distinct neutrophil subpopulations by cancers and other diseases contributes to disease progression $(1,62)$. We demonstrate here that neutrophil heterogeneity can be effectively leveraged for a nanoparticle-based therapy.

\section{Materials and methods}

Mice. We used outbred male CD 1 mice, at a body weight ranging from $34 \mathrm{~g}$ to $38 \mathrm{~g}$ and, for adoptive transfer experiments, male inbred BALB/c mice between 8 and 10 wk of age. Mice were treated in accordance with the NIH Guide for the Care and Use of Laboratory Animals and UIC animal care committee's regulations. All procedures were approved by the UIC IACUC. 
Synthesis of uniform-sized spheric albumin nanoparticles. ANP and PANP, synthesized as described (15), were of consistent hydrodynamic size (120nm $\pm 28 \mathrm{~nm}$ diameter and zeta potential $(-27 \pm 5.48 \mathrm{mV})$ distribution. We injected i.v. $8.3 \mathrm{mg} / \mathrm{kg}$ body weight of ANP, or of ANP loaded with $8.9 \mu \mathrm{M}$ piceatannol (PANP) $1 \mathrm{~h}$ and $2 \mathrm{~h}$ after challenge with LPS or $2 \mathrm{~h}$ and $4 \mathrm{~h}$ after CLP. Flow cytometry and cell sorting. Single cell suspensions were prepared as described (63). Cells were stained for 30 min on ice. Dead cells were excluded by F-SC, S-SC. Neutrophils were gated by Ly6G ${ }^{\text {hi }}$ CD115 $^{\text {lo }}$ S-SChi. Antibodies were from: Bdbiosciences, CCR1; CXCR2; CXCR4; TCR- $\beta$ (H57-597); NK-1.1 (PK136); CD16/CD32 (2.4G2). ebioscience, CD11b (M1/70), CD11c (N418), CD31 (PECAM-1, 390), CD45 (30-F11), CD64, CD115 (AFS98), F4/80 (BM8), MHC II (M5/114.15.2). Biolegend, Ly6C (HK1.4) and Ly6G (1A8). Isotype-matched Abs to irrelevant epitopes were used as negative controls.

Tissue damage markers. The activity, LDH and SDH was determined using commercial kits according to manufacturers' instructions. Histopathology was evaluated in sections from paraffin embedded or frozen tissues using specific antibodies to nitrotyrosine as described (64).

Quantification of hydrogen peroxide production. We measured hydrogen peroxide production using the Amplex Red Hydrogen Peroxide Kit (Invitrogen) following the manufacturer's instructions. Neutrophils were washed and resuspended in HBSS buffer plus $1 \%$ glucose. We incubated $2 \times 10^{4}$ cells with Amplex Red reaction mixture with $10^{-7} \mathrm{M}$ of fMLP at $37^{\circ} \mathrm{C}$ for 5 min prior to measurements with a fluorimetric plate reader at an excitation wavelength of $544 \mathrm{~nm}$ and an emission wavelength of $590 \mathrm{~nm}$. For ex vivo measurement of ROS production we used dihydrorhodamine 123 (65) (66). Male CD1 mice were injected with one i.p. dose of LPS [40mg/kg]; $1 \mathrm{~h}$ and $2 \mathrm{~h}$ later, mice were injected with fluorochrome labeled ANP or PANP as described above; 6 h after LPS challenge, mice were euthanized and heart and lungs were perfused with PBS, excised lung lobes were minced and digested in collagenase solution. Erythrocytes were lysed. Leukocytes were enriched by Ficoll density gradient. Cells were resuspended in HBSS plus $1 \%$ glucose incubated with 
dihydrorhodamine 123 for 20 min at $37^{\circ} \mathrm{C}$ and then immediately processed and analyzed by flow cytometry.

in vivo imaging. Surgical methods to access to the lung are based on Looney et al (28). Tail vein injection with BV421-labeled Ly6G antibody $(10 \mu \mathrm{g} / \mathrm{mouse})$ (1A8, Biolegend) and 70kDa Tetramethylrhodamine-dextran $(200 \mu \mathrm{g} / \mathrm{mice})$ (ThermoFisher Scientific) were performed to stain PMN and lung microvascular structures, respectively, before surgery. A resonant-scanning two photon microscope (Ultima Multiphoton Microscopes, Bruker) with an Olympus XLUMPlanFL N 20x (NA 1.00) collected dual-color images (Emission filter; 460/50 nm for Brilliant Violet 421 and 595/60 $\mathrm{nm}$ for Tetramethylrhodamine) with $820 \mathrm{~nm}$ excitation at video rate. Images were processed and analyzed by image $\mathrm{J}$ and customized LabVIEW programs. For PMN amount analysis, fluorescent intensities of PMN in field of view were quantified and the value of saline injected controls was normalized to 1. For PMN internalizing P/ANP, PMN number with or without P/ANP in field of view was counted and the percentage was calculated. For PMN velocity analysis, PMN velocity of cells migrating more than 1 min in the field of view, was measured.

Adoptive transfer experiments. Donor mice, male BALB/c 8 to 10 wks, were injected with one i.p. dose of LPS $[30 \mathrm{mg} / \mathrm{kg}]$. Prior to euthanasia, mice were injected, into the tail vein, with ANP containing the fluorochrome AF647. After euthanasia, both heart and lungs were perfused with PBS, excised lung lobes were minced and digested in collagenase solution. Erythrocytes were lysed. Syngeneic recipient mice of the same age, were injected, i.p., with a non-lethal dose LPS $[1 \mathrm{mg} / \mathrm{kg}]$ prior to adaptive transfer, i.v., of $8 \times 10^{5}$ ANP ${ }^{\text {high }}$ or an equal number of ANPlow granulocytes. Transcriptomic profiling. Mice were injected i.p. with LPS (12 mg/kg) or a saline, ANP were injected i.v. 1h before mice were euthanized. PMN were harvested form lungs and by flow cytometry sorting of Ly6G ${ }^{\text {pos }}$ divided into ANPhigh and ANPlow PMN. mRNA was isolated and prepared immediately for RNA-Seq or qPCR analysis. RNA-Seq. Raw reads were aligned to reference genome mm10 using STAR (67). Gene expression was quantified using FeatureCounts (68) against Ensemble coding and non-coding gene annotations. Differential expression between 
nanoparticle dye selection positive and negative was computed using edgeR $(69,70)$, adjusting for technical batch effect due to mouse cohort selection; normalized gene expression was reported in log2 CPM units. P-values were adjusted for multiple testing using the false discovery rate (FDR) correction of Benjamini and Hochberg (71). Significant genes were determined based on an FDR threshold of $5 \%(0.05)$. All genes that were differentially expressed due to nanoparticle dye selection, in either LPS treated or untreated animals, were visualized in a heatmap, including dendrograms from complete linkage hierarchical clustering for both genes and samples. In addition, separate heatmaps for chemokine ligands and chemokine receptors were generated, plotting all genes with $\mathrm{CPM}>0.25$ (10 reads at a sequencing depth of $40 \mathrm{M}$ reads) regardless of differential expression levels. LPS treated animals were separated from untreated animals in these heatmaps to highlight the effect of nanoparticle dye selection on the expression levels. qPCR. mRNA was extracted from sorted PMN using the Qiagen RNeasy Mini Kit. Total RNA quantity was measured at $260 \mathrm{~nm}$ and purity was assessed by the optical density $260 \mathrm{~nm} / \mathrm{optical}$ density $280 \mathrm{~nm}$ ratio. $0.5 \mu \mathrm{g}$ of RNA was transcribed to complementary DNA with random primers using the High-Capacity cDNA Reverse Transcription Kit (ThermoFischer). Quantitative gene expression was evaluated by qPCR using the QuantStudio 7 Flex Real-Time PCR System. Results were calculated using the

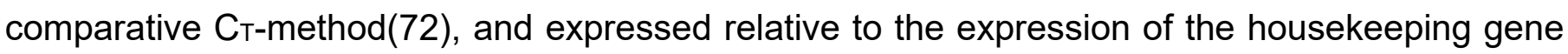
Ppia (ENSMUSG00000071866.12). We used the following primers, forward, and reverse, respectively: Ppia GGCAAATGCTGGACCAAACAC, TTCCTGGACCCAAAACGCTC: $\quad \| 1 \mathrm{~b}$ TGGGAAACAACAGTGGTCAG, CAAGGAGGAAAACACAGGCT; Cor1 CAACCTGGCTGTCTCTGATC, GCATGGAAGCTAAGATGGCT;

CAATTCTCTGCGCCCAAAAG, TCTTAAGGACCTCACCAGC; Ccl3 AGAAGGATACAAGCAGCAGC, GACTTGGTTGCAGAGTGTCA; Ccl4 GATCTGTGCTAACCCCAGTG, AGAAGAGGGGCAGGAAATCT; Cxcl2 AGTTTGCCTTGACCCTGAAG, GTGAACTCTCAGACAGCGA; Cxcl3 
Statistical analysis. We examined the differences between groups for statistical significance by

Student's t-test or ANOVA, and compared survival curves with a log-rank test. Enrichment of chemokine receptor or chemokine expression in the ANPhigh and ANPlow groups was assessed by Fisher's Exact Test. A $p$ value of $<0.05$ was considered statistically significant.

\section{Acknowledgements:}

We thank Dr. Paul Frenette of Albert Einstein College of Medicine for helpful comments.

Funding: This work was supported by the US National Institutes of Health (T32 HL007829, R41HL118896, R41HL126456, R42HL126456, R01HL149300).

Competing interests: The authors declare no competing interests. ABM, AS, KB have interests in the biotechnology company Nano Biotherapeutics Inc.

\section{Video}

Two-photon microscopy of perfused, ventilated lungs from endotoxemic mice and saline-injected controls. mice were injected with LPS [30mg/kg], 6h prior to, and with ANP or PANP $3 \mathrm{~h}$ and $4 \mathrm{~h}$ prior to in vivo imaging. Dextran traces blood vessels, outlining lung microvascular structures, blue; fluorescent-labeled Ly6G Abs label PMN, green; fluorochrome AF647 labels ANP or PANP, red.

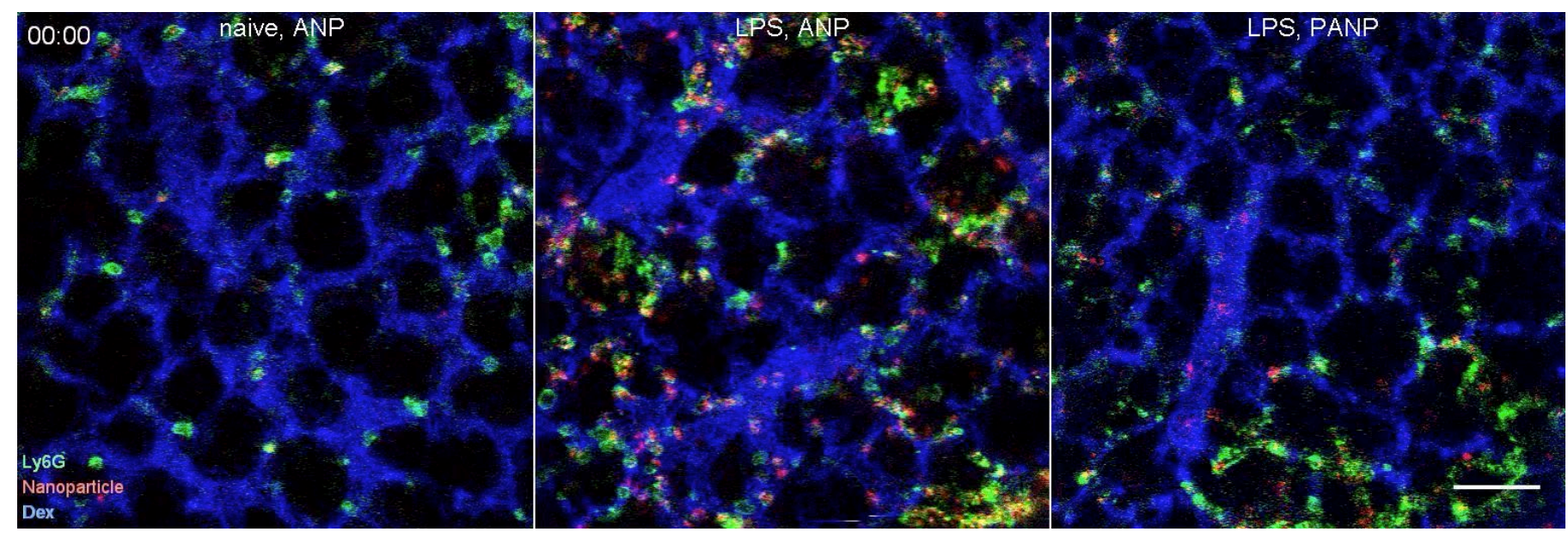


Colors are pseudocolors. Bar measures $50 \mu \mathrm{m}$. Representative data from a minimum or 4 mice per

treatment group.

\section{References}

1. Ng LG, Ostuni R, and Hidalgo A. Heterogeneity of neutrophils. Nature Reviews Immunology. 2019;19(4):255-65.

2. Summers C, Rankin SM, Condliffe AM, Singh N, Peters AM, and Chilvers ER. Neutrophil kinetics in health and disease. Trends Immunol. 2010;31(8):318-24.

3. Leliefeld PHC, Wessels CM, Leenen LPH, Koenderman L, and Pillay J. The role of neutrophils in immune dysfunction during severe inflammation. Crit Care. 2016;20:73-.

4. Abraham E. Neutrophils and acute lung injury. Critical Care Medicine. 2003;31(4):S195-S9.

5. Deutschman CS, and Tracey KJ. Sepsis: Current Dogma and New Perspectives. Immunity. 2014;40(4):464-76.

6. Dellinger RP, Levy MM, Rhodes A, Annane D, Gerlach H, Opal SM, et al. Surviving Sepsis Campaign: International Guidelines for Management of Severe Sepsis and Septic Shock: 2012. Critical Care Medicine. 2013;41(2):580-637.

7. Ranieri VM, Thompson BT, Barie PS, Dhainaut JF, Douglas IS, Finfer S, et al. Drotrecogin Alfa (Activated) in Adults with Septic Shock. N Engl J Med. 2012;366(22):2055-64.

8. Gotts JE, and Matthay MA. Sepsis: pathophysiology and clinical management. Bmj-British Medical Journal. 2016;353.

9. Karlin L, Darmon M, Thiéry G, Ciroldi M, de Miranda S, Lefebvre A, et al. Respiratory status deterioration during G-CSF-induced neutropenia recovery. Bone Marrow Transplantation. 2005;36(3):245-50.

10. Yamashiro S, Kamohara H, Wang J-M, Yang D, Gong W-H, and Yoshimura T. Phenotypic and functional change of cytokine-activated neutrophils: inflammatory neutrophils are heterogeneous and enhance adaptive immune responses. Journal of Leukocyte Biology. 2001;69(5):698-704.

11. Ley K, Laudanna C, Cybulsky MI, and Nourshargh S. Getting to the site of inflammation: the leukocyte adhesion cascade updated. Nature Reviews Immunology. 2007;7:678.

12. Mayadas TN, Cullere X, and Lowell CA. In: Abbas AK, Galli SJ, and Howley PM eds. Annual Review of Pathology: Mechanisms of Disease, Vol 9. 2014:181-218.

13. Silvestre-Roig C, Hidalgo A, and Soehnlein O. Neutrophil heterogeneity: implications for homeostasis and pathogenesis. Blood. 2016;127(18):2173-81.

14. Nicolas-Avila JA, Adrover JM, and Hidalgo A. Neutrophils in Homeostasis, Immunity, and Cancer. Immunity. 2017;46(1):15-28.

15. Wang Z, Li J, Cho J, and Malik AB. Prevention of vascular inflammation by nanoparticle targeting of adherent neutrophils. Nat Nano. 2014;9(3):204-10.

16. Bone RC. THE PATHOGENESIS OF SEPSIS. Ann Intern Med. 1991;115(6):457-69.

17. Guan E, Wang J, and Norcross MA. Identification of Human Macrophage Inflammatory Proteins $1 \alpha$ and $1 \beta$ as a Native Secreted Heterodimer. Journal of Biological Chemistry. 2001;276(15):12404-9.

18. Andonegui G, Bonder CS, Green F, Mullaly SC, Zbytnuik L, Raharjo E, et al. Endothelium-derived toll-like receptor-4 is the key molecule in LPS-induced neutrophil sequestration into lungs. Journal Of Clinical Investigation. 2003;111(7):1011-20.

19. Mittal M, Siddiqui MR, Tran K, Reddy SP, and Malik AB. Reactive Oxygen Species in 
Inflammation and Tissue Injury. Antioxid Redox Signal. 2014;20(7):1126-67.

20. Belperio JA, Keane MP, Burdick MD, Londhe V, Xue YY, Li KW, et al. Critical role for CXCR2 and CXCR2 ligands during the pathogenesis of ventilator-induced lung injury. Journal Of Clinical Investigation. 2002;110(11):1703-16.

21. Reutershan J, Morris MA, Burcin TL, Smith DF, Chang D, Saprito MS, et al. Critical role of endothelial CXCR2 in LPS-induced neutrophil migration into the lung. Journal of Clinical Investigation. 2006;116(3):695-702.

22. Cheng KT, Xiong SQ, Ye ZM, Hong ZG, Di AK, Tsang KM, et al. Caspase-11-mediated endothelial pyroptosis underlies endotoxemia-induced lung injury. Journal of Clinical Investigation. 2017;127(11):4124-35.

23. Luo BH, Carman CV, and Springer TA. Annual Review of Immunology. 2007:619-47.

24. Mocsai A, Zhou MJ, Meng FY, Tybulewicz VL, and Lowell CA. Syk is required for integrin signaling in neutrophils. Immunity. 2002;16(4):547-58.

25. Oliver JM, Burg DL, Wilson BS, McLaughlin JL, and Geahlen RL. INHIBITION OF MAST-CELL FC-EPSILON-R1-MEDIATED SIGNALING AND EFFECTOR FUNCTION BY THE SYKSELECTIVE INHIBITOR, PICEATANNOL. Journal of Biological Chemistry. 1994;269(47):29697-703.

26. Seow C-J, Chue S-C, and Wong WSF. Piceatannol, a Syk-selective tyrosine kinase inhibitor, attenuated antigen challenge of guinea pig airways in vitro. European Journal of Pharmacology. 2002;443(1):189-96.

27. Geahlen RL, and McLaughlin JL. PICEATANNOL (3,4,3',5'-TETRAHYDROXY-TRANSSTILBENE) IS A NATURALLY-OCCURRING PROTEIN-TYROSINE KINASE INHIBITOR. Biochem Biophys Res Commun. 1989;165(1):241-5.

28. Looney MR, Thornton EE, Sen D, Lamm WJ, Glenny RW, and Krummel MF. Stabilized imaging of immune surveillance in the mouse lung. Nature methods. 2011;8(1):91-6.

29. Shiloh MU, MacMicking JD, Nicholson S, Brause JE, Potter S, Marino M, et al. Phenotype of mice and macrophages deficient in both phagocyte oxidase and inducible nitric oxide synthase. Immunity. 1999;10(1):29-38.

30. Yipp BG, Kim JH, Lima R, Zbytnuik LD, Petri B, Swanlund N, et al. The lung is a host defense niche for immediate neutrophil-mediated vascular protection. Science Immunology. 2017;2(10).

31. Elting LS, Rubenstein EB, Rolston KV, and Bodey GP. Outcomes of bacteremia in patients with cancer and neutropenia: observations from two decades of epidemiological and clinical trials. Clinical infectious diseases : an official publication of the Infectious Diseases Society of America. 1997;25(2):247-59.

32. Haddad IY, Pataki G, Hu P, Galliani C, Beckman JS, and Matalon S. QUANTITATION OF NITROTYROSINE LEVELS IN LUNG SECTIONS OF PATIENTS AND ANIMALS WITH ACUTE LUNG INJURY. Journal of Clinical Investigation. 1994;94(6):2407-13.

33. Matthay MA, Ware LB, and Zimmerman GA. The acute respiratory distress syndrome. Journal of Clinical Investigation. 2012;122(8):2731-40.

34. Zein JG, Lee GL, Tawk M, Dabaja M, and Kinasewitz GT. Prognostic Significance of Elevated Serum Lactate Dehydrogenase (LDH) in Patients with Severe Sepsis. CHEST. 2004;126(4):873S.

35. Gadberry MG, DeNicola DB, and Carlson GP. Pneumotoxicity and hepatotoxicity of styrene and styrene oxide. J Toxicol Environ Health. 1996;48(3):273-94.

36. Williams AE, and Chambers RC. The mercurial nature of neutrophils: still an enigma in ARDS? American Journal of Physiology-Lung Cellular and Molecular Physiology. 2014;306(3):L217-L30.

37. Kruger P, Saffarzadeh M, Weber ANR, Rieber N, Radsak M, von Bernuth H, et al. Neutrophils: Between Host Defence, Immune Modulation, and Tissue Injury. Plos Pathogens. 2015;11(3).

38. Scapini P, and Cassatella MA. Social networking of human neutrophils within the immune system. Blood. 2014;124(5):710-9.

39. Beyrau M, Bodkin JV, and Nourshargh S. Neutrophil heterogeneity in health and disease: a revitalized avenue in inflammation and immunity. Open Biology. 2012;2. 
40. Kolaczkowska E, and Kubes P. Neutrophil recruitment and function in health and inflammation. Nature Reviews Immunology. 2013;13(3):159-75.

41. Bhatia M, and Moochhala S. Role of inflammatory mediators in the pathophysiology of acute respiratory distress syndrome. Journal Of Pathology. 2004;202(2):145-56.

42. Allen NC, Philip NH, Hui L, Zhou X, Franklin RA, Kong Y, et al. Desynchronization of the molecular clock contributes to the heterogeneity of the inflammatory response. Sci Signal. 2019;12(571):10.

43. Shi C, and Pamer EG. Monocyte recruitment during infection and inflammation. Nature Reviews Immunology. 2011;11(11):762-74.

44. Wu D, Wu T, Liu Q, and Yang Z. The SARS-CoV-2 outbreak: What we know. International Journal of Infectious Diseases. 2020;94:44-8.

45. Wang D, Hu B, Hu C, Zhu F, Liu X, Zhang J, et al. Clinical Characteristics of 138 Hospitalized Patients With 2019 Novel Coronavirus-Infected Pneumonia in Wuhan, China. JAMA : the journal of the American Medical Association. 2020;323(11):1061-9.

46. Moore JB, and June CH. Cytokine release syndrome in severe COVID-19. Science. 2020;368(6490):473.

47. Coperchini F, Chiovato L, Croce L, Magri F, and Rotondi M. The cytokine storm in COVID-19: An overview of the involvement of the chemokine/chemokine-receptor system. Cytokine \& Growth Factor Reviews. 2020;53:25-32.

48. Hidalgo A, Chang J, Jang JE, Peired AJ, Chiang EY, and Frenette PS. Heterotypic interactions enabled by polarized neutrophil microdomains mediate thromboinflammatory injury. Nature medicine. 2009;15(4):384-91.

49. Whyte MK, Meagher LC, MacDermot J, and Haslett C. Impairment of function in aging neutrophils is associated with apoptosis. $J$ Immunol. 1993;150(11):5124-34.

50. Zhang D, Chen G, Manwani D, Mortha A, Xu C, Faith JJ, et al. Neutrophil ageing is regulated by the microbiome. Nature. 2015;525(7570):528-32.

51. Van Ziffle JA, and Lowell CA. Neutrophil-specific deletion of Syk kinase results in reduced host defense to bacterial infection. Blood. 2009;114(23):4871-82.

52. Medzhitov R, Schneider DS, and Soares MP. Disease Tolerance as a Defense Strategy. Science. 2012;335(6071):936-41.

53. Schneider DS, and Ayres JS. Two ways to survive infection: what resistance and tolerance can teach us about treating infectious diseases. Nature Reviews Immunology. 2008;8(11):889-95.

54. Vinten-Johansen J. Involvement of neutrophils in the pathogenesis of lethal myocardial reperfusion injury. Cardiovasc Res. 2004;61(3):481-97.

55. Natanson C, Hoffman WD, Suffredini AF, Eichacker PQ, and Danner RL. SELECTED TREATMENT STRATEGIES FOR SEPTIC SHOCK BASED ON PROPOSED MECHANISMS OF PATHOGENESIS. Ann Intern Med. 1994;120(9):771-83.

56. Rhodes A, Evans LE, Alhazzani W, Levy MM, Antonelli M, Ferrer R, et al. Surviving Sepsis Campaign: International Guidelines for Management of Sepsis and Septic Shock: 2016. Intensive Care Med. 2017;43(3):304-77.

57. Opal SM, Laterre PF, Francois B, LaRosa SP, Angus DC, Mira JP, et al. Effect of eritoran, an antagonist of MD2-TLR4, on mortality in patients with severe sepsis: the ACCESS randomized trial. JAMA : the journal of the American Medical Association. 2013;309(11):1154-62.

58. Rice TW, Wheeler AP, Bernard GR, Vincent JL, Angus DC, Aikawa N, et al. A randomized, double-blind, placebo-controlled trial of TAK-242 for the treatment of severe sepsis. Critical Care Medicine. 2010;38(8):1685-94.

59. Reinhart K, and Karzai W. Anti-tumor necrosis factor therapy in sepsis: Update on clinical trials and lessons learned. Critical Care Medicine. 2001;29(7):S121-S5.

60. Wilson JG, Liu KD, Zhuo NJ, Caballero L, McMillan M, Fang XH, et al. Mesenchymal stem (stromal) cells for treatment of ARDS: a phase 1 clinical trial. Lancet Resp Med. 2015;3(1):24-32.

61. Sabroe I, Prince LR, Jones EC, Horsburgh MJ, Foster SJ, Vogel SN, et al. Selective roles for toll- 
like receptor (TLR) 2 and TLR4 in the regulation of neutrophil activation and life span. $J$ Immunol. 2003;170(10):5268-75.

62. Silvestre-Roig C, Fridlender ZG, Glogauer M, and Scapini P. Neutrophil Diversity in Health and Disease. Trends Immunol. 2019;40(7):565-83.

63. Bachmaier K, Toya S, Gao XP, Triantafillou T, Garrean S, Park GY, et al. E3 ubiquitin ligase Cblb regulates the acute inflammatory response underlying lung injury. Nature medicine.

2007;13(8):920-6.

64. Bachmaier K, Neu N, Pummerer C, Duncan GS, Mak TW, Matsuyama T, et al. iNOS expression and nitrotyrosine formation in the myocardium in response to inflammation is controlled by the interferon regulatory transcription factor 1. Circulation. 1997;96(2):585-91.

65. Chen Y, and Junger WG. Measurement of Oxidative Burst in Neutrophils. Methods in molecular biology (Clifton, NJ). 2012;844:115-24.

66. Vowells SJ, Sekhsaria S, Malech HL, Shalit M, and Fleisher TA. FLOW CYTOMETRIC ANALYSIS OF THE GRANULOCYTE RESPIRATORY BURST - A COMPARISON STUDY OF FLUORESCENT-PROBES. J Immunol Methods. 1995;178(1):89-97.

67. Dobin A, Davis CA, Schlesinger F, Drenkow J, Zaleski C, Jha S, et al. STAR: ultrafast universal RNA-seq aligner. Bioinformatics. 2013;29(1):15-21.

68. Liao Y, Smyth GK, and Shi W. featureCounts: an efficient general purpose program for assigning sequence reads to genomic features. Bioinformatics. 2014;30(7):923-30.

69. McCarthy DJ, Chen Y, and Smyth GK. Differential expression analysis of multifactor RNA-Seq experiments with respect to biological variation. Nucleic Acids Res. 2012;40(10):4288-97.

70. Robinson MD, McCarthy DJ, and Smyth GK. edgeR: a Bioconductor package for differential expression analysis of digital gene expression data. Bioinformatics. 2010;26(1):139-40.

71. Benjamini Y, and Hochberg Y. Controlling the false discovery rate: a practical and powerful approach to multiple testing. Journal of the royal statistical society Series B (Methodological). 1995:289-300.

72. Schmittgen TD, and Livak KJ. Analyzing real-time PCR data by the comparative CT method. Nature Protocols. 2008;3:1101. 


\section{Supplemental Figures}

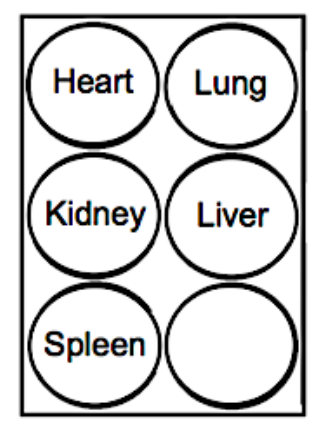

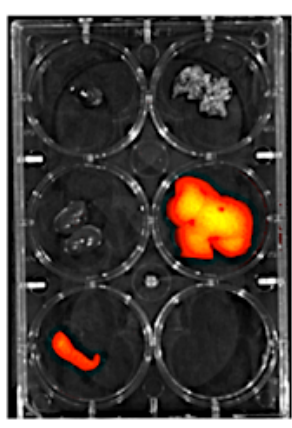

Naïve, ANP

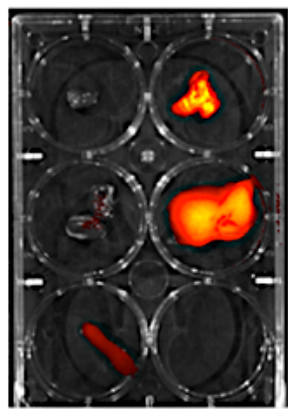

LPS, ANP

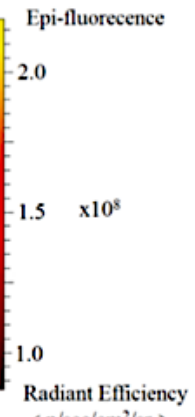

$\left(\frac{\mathrm{p} / \mathrm{sec} / \mathrm{cm}^{2} / \mathrm{sr}}{\mu \mathrm{W} / \mathrm{cm}^{2}}\right)$

Supplemental Figure 1. ANP Biodistribution Measured by IVIS In naïve mice, i.v.-injected ANPs were mostly found to liver and spleen. After i.p. administration of the endotoxin LPS $[30 \mathrm{mg} / \mathrm{kg}]$, ANP appeared prominently in lungs, and remained visible in liver and in spleen. Albumin was labeled with vivotag 800 (PerkinElmer) and then formed into ANPs. Organs were harvested $4 \mathrm{~h}$ after $150 \mu \mathrm{l}$ tail vein injection of $2 \mathrm{mg} / \mathrm{ml}$ vivotag 800 labeled ANPs. Epi-fluorescence radiance scale corresponding to images. Fluorescence was measured by a Xenogen IVIS Spectrum (Caliper Life Sciences) and images were processed with Living Image software (ver. 4.3.1). An excitation filter of $785 \mathrm{~nm}$ and emission filter of $820 \mathrm{~nm}$ with $120 \mathrm{sec}$ exposure times were used for all experiments. Representative data obtained from at least 3 mice per treatment group. 


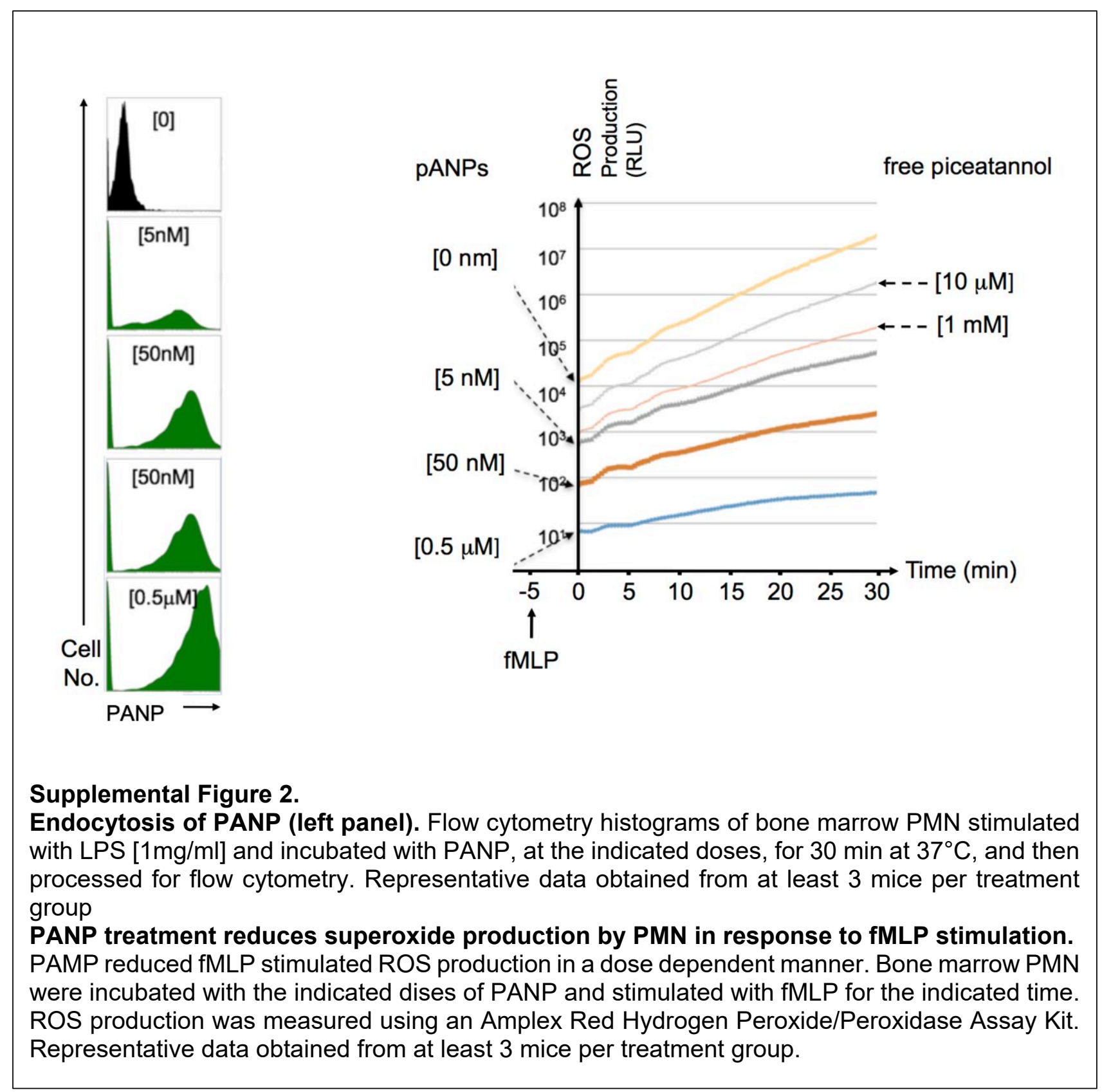




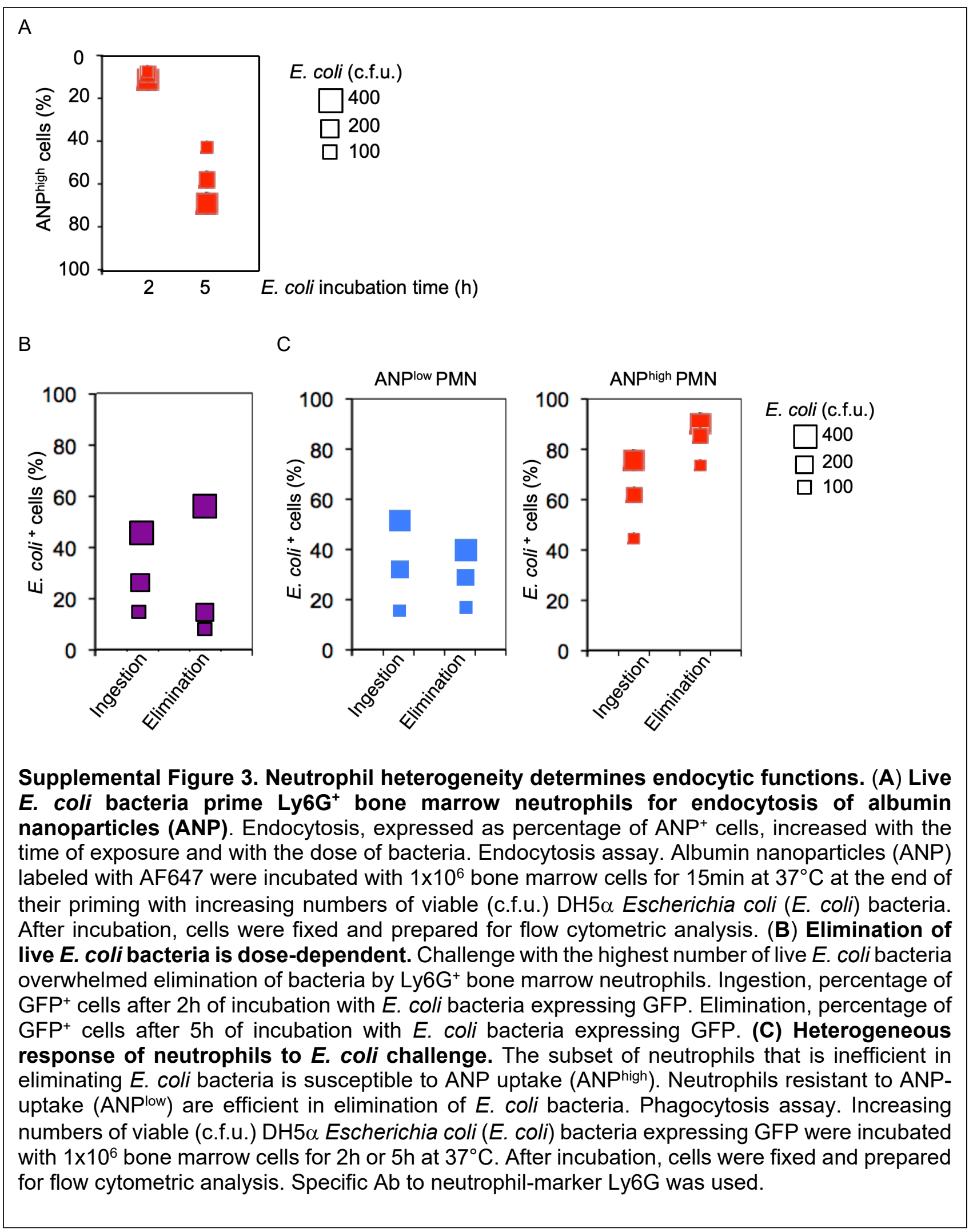




\begin{tabular}{|c|c|c|}
\hline \multicolumn{2}{|c|}{ Supplemental Table } & \multirow[b]{3}{*}{ Total } \\
\hline \multicolumn{2}{|c|}{ Enrichment by Pathway Maps } & \\
\hline$\#$ & Maps & \\
\hline 1 & Breakdown of CD4+ T cell peripheral tolerance in type 1 diabetes mellitus & 49 \\
\hline 2 & Immune response IFN-alpha/beta signaling via JAK/STAT & 64 \\
\hline 3 & Immune response Generation of memory $\mathrm{CD} 4+\mathrm{T}$ cells & 37 \\
\hline 4 & CHDI Correlations from Replication data Causal network (positive correlat & 79 \\
\hline 5 & Immune response TCR alpha/beta signaling pathway & 58 \\
\hline 6 & Immune response $T$ cell subsets: cell surface markers & 52 \\
\hline 7 & Immune response Role of DPP4 (CD26) in immune regulation & 47 \\
\hline 8 & Immune response IFN-alpha/beta signaling via MAPKs & 77 \\
\hline 9 & Rheumatoid arthritis (general schema) & 50 \\
\hline 10 & The role of KEAP1/NRF2 pathway in skin sensitization & 32 \\
\hline 11 & Immune response NF-AT in immune response & 51 \\
\hline 12 & Chemokines in inflammation in adipose tissue and liver in obesity, type $2 d$ & 48 \\
\hline 13 & T follicular helper cell dysfunction in SLE & 90 \\
\hline 14 & Memory CD8+ T cells in allergic contact dermatitis & 40 \\
\hline 15 & Immune response CD28 signaling & 55 \\
\hline 16 & Maturation and migration of dendritic cells in skin sensitization & 41 \\
\hline 17 & Vascular endothelial cell damage in SLE & 63 \\
\hline 18 & Putative role of Tregs in COPD & 30 \\
\hline
\end{tabular}




\begin{tabular}{|c|c|c|}
\hline 19 & Aberrant production of IL-2 and IL-17 in SLE T cells & 58 \\
\hline 20 & SLE genetic marker-specific pathways in T cells & 101 \\
\hline 21 & Attenuation of IFN type I signaling in melanoma cells & 37 \\
\hline 22 & Immune response IL-3 signaling via JAK/STAT, p38, JNK and NF-kB & 93 \\
\hline 23 & Immune response Inhibitory PD-1 signaling in T cells & 53 \\
\hline 24 & Immune response OX40L/ OX40 signaling pathway & 69 \\
\hline 25 & Immune response Role of HMGB1 in dendritic cell maturation and migratid & 26 \\
\hline 26 & CD8+ Tc1 cells in allergic contact dermatitis & 26 \\
\hline 27 & Immune response HSP60 and HSP70/ TLR signaling pathway & 54 \\
\hline 28 & NRF2 regulation of oxidative stress response & 54 \\
\hline 29 & Chemotaxis SDF-1/ CXCR4-induced chemotaxis of immune cells & 79 \\
\hline 30 & Resistance of pancreatic cancer cells to death receptor signaling & 33 \\
\hline 31 & Immune response T cell co-signaling receptors, schema & 55 \\
\hline 32 & Immune response NF-AT signaling and leukocyte interactions & 48 \\
\hline 33 & Role of Apo-2L(TNFSF10) in Prostate Cancer cell apoptosis & 34 \\
\hline 34 & Renal tubulointerstitial injury in Lupus Nephritis & 65 \\
\hline 35 & Immune response Differentiation of natural regulatory $T$ cells & 35 \\
\hline 36 & Inhibition of apoptosis in gastric cancer & 42 \\
\hline 37 & IL-1 signaling in melanoma & 42 \\
\hline 38 & Immune response IL-15 signaling & 58 \\
\hline 39 & Immune response CD137 signaling in immune cell & 29 \\
\hline
\end{tabular}




\begin{tabular}{|r|l|r|}
\hline 40 & Apoptosis and survival TNFR1 signaling pathway & \\
\hline 41 & Role of TLR signaling in skin sensitization & 43 \\
\hline 42 & Immune response ICOS signaling pathway in T-helper cell & 44 \\
\hline 43 & IL-6 signaling in colorectal cancer & 60 \\
\hline 44 & Macrophage-induced immunosuppression in the tumor microenvironment & \\
\hline 45 & Immune response TLR2 and TLR4 signaling pathways & \\
\hline & & \\
\hline 46 & Stellate cells activation and liver fibrosis & 66 \\
\hline & & \\
\hline 47 & Immune response IL-2 signaling via JAK/ STAT & \\
\hline & & \\
\hline 48 & Role of keratinocytes and Langerhans cells in skin sensitization & \\
\hline 49 & Role of IL-23/ T17 pathogenic axis in psoriasis & \\
\hline 50 & Macrophage and dendritic cell phenotype shift in cancer & \\
\hline & & \\
\hline
\end{tabular}




\begin{tabular}{|c|c|c|c|c|c|}
\hline $\min (p$ Value $)$ & Min FDR & p-value & FDR & In Data & $\begin{array}{l}\text { Network Objects } \\
\text { from }\end{array}$ \\
\hline 1.067E-12 & 1.426E-09 & 1.015E-01 & $2.928 \mathrm{E}-01$ & 2 & HLA-DRB1, PD-L1 \\
\hline $2.804 \mathrm{E}-11$ & 1.873E-08 & $3.348 \mathrm{E}-02$ & 1.843E-01 & 3 & RSAD2, IFNAR1, Bax \\
\hline $1.258 \mathrm{E}-10$ & $5.602 \mathrm{E}-08$ & $3.368 \mathrm{E}-01$ & 4.795E-01 & 1 & IL-15 \\
\hline $2.681 \mathrm{E}-10$ & $8.433 \mathrm{E}-08$ & 1.766E-03 & $5.029 \mathrm{E}-02$ & 5 & IRAK $1 / 2$, CD83, ICAI \\
\hline $3.156 \mathrm{E}-10$ & $8.433 \mathrm{E}-08$ & $4.750 \mathrm{E}-01$ & 5.191E-01 & 1 & MALT1 \\
\hline $3.933 \mathrm{E}-10$ & $8.758 \mathrm{E}-08$ & 4.387E-01 & $5.042 \mathrm{E}-01$ & 1 & CXCR3 \\
\hline $6.548 \mathrm{E}-10$ & $1.250 \mathrm{E}-07$ & $1.490 \mathrm{E}-02$ & $1.301 \mathrm{E}-01$ & 3 & MALT1, TNF-alpha, I \\
\hline $1.121 \mathrm{E}-09$ & 1.873E-07 & $2.083 \mathrm{E}-01$ & 4.304E-01 & 2 & RSAD2, IFNAR1 \\
\hline 1.857E-09 & $2.756 \mathrm{E}-07$ & $1.701 \mathrm{E}-05$ & 3.493E-03 & 6 & IL-15, ICAM1, MHC c \\
\hline 2.147E-09 & 2.869E-07 & $2.384 \mathrm{E}-05$ & 3.493E-03 & 5 & MafF, MafK, HSP70, \\
\hline $2.578 \mathrm{E}-09$ & $3.132 \mathrm{E}-07$ & $1.000 \mathrm{E}+00$ & $1.000 \mathrm{E}+00$ & 0 & \\
\hline 8.664E-09 & $9.646 \mathrm{E}-07$ & 1.337E-05 & 3.493E-03 & 6 & ITGA4, ITGAX, ICAM \\
\hline $2.070 \mathrm{E}-08$ & $2.128 \mathrm{E}-06$ & $2.612 \mathrm{E}-01$ & 4.662E-01 & 2 & MALT1, BATF \\
\hline $5.081 \mathrm{E}-08$ & 4.849E-06 & 9.597E-03 & $9.525 \mathrm{E}-02$ & 3 & IL-15, ICAM1, TNF-al \\
\hline $6.744 \mathrm{E}-08$ & 5.814E-06 & $1.000 \mathrm{E}+00$ & $1.000 \mathrm{E}+00$ & 0 & \\
\hline 7.094E-08 & 5.814E-06 & 8.194E-05 & $7.668 \mathrm{E}-03$ & 5 & CD83, ICAM1, MHC c \\
\hline 7.399E-08 & $5.814 \mathrm{E}-06$ & $5.077 \mathrm{E}-03$ & 7.341E-02 & 4 & ICAM1, PD-L1, CSF1 \\
\hline $1.341 \mathrm{E}-07$ & $9.951 \mathrm{E}-06$ & $1.000 \mathrm{E}+00$ & $1.000 \mathrm{E}+00$ & 0 & \\
\hline
\end{tabular}




\begin{tabular}{|c|c|c|c|c|c|}
\hline $1.461 \mathrm{E}-07$ & $1.027 \mathrm{E}-05$ & $1.000 \mathrm{E}+00$ & $1.000 \mathrm{E}+00$ & 0 & \\
\hline $1.595 \mathrm{E}-07$ & $1.066 \mathrm{E}-05$ & $3.062 \mathrm{E}-01$ & $4.788 \mathrm{E}-01$ & 2 & MHC class II beta cha \\
\hline $1.718 \mathrm{E}-07$ & 1.093E-05 & $3.368 \mathrm{E}-01$ & 4.795E-01 & 1 & IFNAR1 \\
\hline $1.941 \mathrm{E}-07$ & $1.179 \mathrm{E}-05$ & $6.447 \mathrm{E}-01$ & 6.497E-01 & 1 & ICAM1 \\
\hline 2.864E-07 & $1.535 \mathrm{E}-05$ & $1.156 \mathrm{E}-01$ & 3.117E-01 & 2 & ICAM1, PD-L1 \\
\hline 2.897E-07 & $1.535 \mathrm{E}-05$ & $1.763 \mathrm{E}-01$ & 4.024E-01 & 2 & CXCR4, MALT1 \\
\hline 2.987E-07 & $1.535 \mathrm{E}-05$ & $2.824 \mathrm{E}-03$ & $6.568 \mathrm{E}-02$ & 3 & IL-15, CXCR4, TNF-a \\
\hline 2.987E-07 & $1.535 \mathrm{E}-05$ & $2.506 \mathrm{E}-01$ & $4.598 \mathrm{E}-01$ & 1 & TNF-alpha \\
\hline 3.687E-07 & $1.759 \mathrm{E}-05$ & 2.667E-05 & $3.493 \mathrm{E}-03$ & 6 & IRAK1/2, CD83, ICAN \\
\hline 3.687E-07 & $1.759 \mathrm{E}-05$ & 2.156E-02 & $1.552 \mathrm{E}-01$ & 3 & MafF, MafK, Heme ox \\
\hline 3.906E-07 & $1.799 \mathrm{E}-05$ & 2.164E-01 & 4.378E-01 & 2 & ICAM1, CXCR4 \\
\hline 4.124E-07 & $1.837 \mathrm{E}-05$ & 3.067E-01 & 4.788E-01 & 1 & Bax \\
\hline 4.715E-07 & 2.032E-05 & $3.110 \mathrm{E}-03$ & $6.570 \mathrm{E}-02$ & 4 & LAIR1, TIM-3, CD244 \\
\hline $5.569 \mathrm{E}-07$ & $2.325 \mathrm{E}-05$ & $1.000 \mathrm{E}+00$ & $1.000 \mathrm{E}+00$ & 0 & \\
\hline $5.816 \mathrm{E}-07$ & $2.355 \mathrm{E}-05$ & 3.143E-01 & 4.788E-01 & 1 & Bax \\
\hline 7.283E-07 & 2.862E-05 & $3.482 \mathrm{E}-02$ & $1.882 \mathrm{E}-01$ & 3 & ICAM1, CSF1, TNF-al \\
\hline $8.092 \mathrm{E}-07$ & 2.922E-05 & $3.219 \mathrm{E}-01$ & 4.795E-01 & 1 & TIEG1 \\
\hline 8.093E-07 & 2.922E-05 & $3.727 \mathrm{E}-01$ & 4.866E-01 & 1 & Bax \\
\hline 8.093E-07 & 2.922E-05 & $1.098 \mathrm{E}-02$ & $1.073 \mathrm{E}-01$ & 3 & ICAM1, GRO-2, PD-L \\
\hline $9.522 \mathrm{E}-07$ & $3.348 \mathrm{E}-05$ & $1.340 \mathrm{E}-01$ & $3.408 \mathrm{E}-01$ & 2 & IL-15, ADAM17 \\
\hline $9.790 \mathrm{E}-07$ & 3.354E-05 & $2.751 \mathrm{E}-01$ & 4.730E-01 & 1 & TRAF1 \\
\hline
\end{tabular}




\begin{tabular}{|c|c|c|c|c|c|}
\hline $1.071 \mathrm{E}-06$ & $3.576 \mathrm{E}-05$ & $8.124 \mathrm{E}-02$ & $2.743 \mathrm{E}-01$ & 2 & TNF-alpha, Bax \\
\hline $1.404 \mathrm{E}-06$ & 4.576E-05 & $1.246 \mathrm{E}-02$ & 1.150E-01 & 3 & IRAK1/2, HSP70, TN \\
\hline $1.480 \mathrm{E}-06$ & 4.667E-05 & 4.866E-01 & 5.191E-01 & 1 & TNF-alpha \\
\hline $1.509 \mathrm{E}-06$ & 4.667E-05 & 7.014E-04 & $3.281 \mathrm{E}-02$ & 4 & ICAM1, HSP70, Bax, \\
\hline $1.537 \mathrm{E}-06$ & 4.667E-05 & 4.130E-03 & $7.310 \mathrm{E}-02$ & 5 & CD68, CXCR4, Calcip \\
\hline $1.645 \mathrm{E}-06$ & 4.883E-05 & 7.005E-03 & 8.086E-02 & 4 & IRAK2, TPL2(MAP3K \\
\hline 1.996E-06 & $5.796 \mathrm{E}-05$ & 1.127E-05 & $3.493 \mathrm{E}-03$ & 7 & IRAK1/2, ICAM1, GR \\
\hline $2.285 \mathrm{E}-06$ & $6.359 \mathrm{E}-05$ & $1.000 \mathrm{E}+00$ & $1.000 \mathrm{E}+00$ & 0 & \\
\hline 2.285E-06 & $6.359 \mathrm{E}-05$ & 2.422E-01 & 4.494E-01 & 1 & TNF-alpha \\
\hline $2.406 \mathrm{E}-06$ & $6.560 \mathrm{E}-05$ & 1.192E-01 & $3.175 \mathrm{E}-01$ & 2 & IL-15, ADAM17 \\
\hline $2.843 \mathrm{E}-06$ & $7.499 \mathrm{E}-05$ & $3.021 \mathrm{E}-01$ & 4.788E-01 & 2 & CSF1, TNF-alpha \\
\hline
\end{tabular}




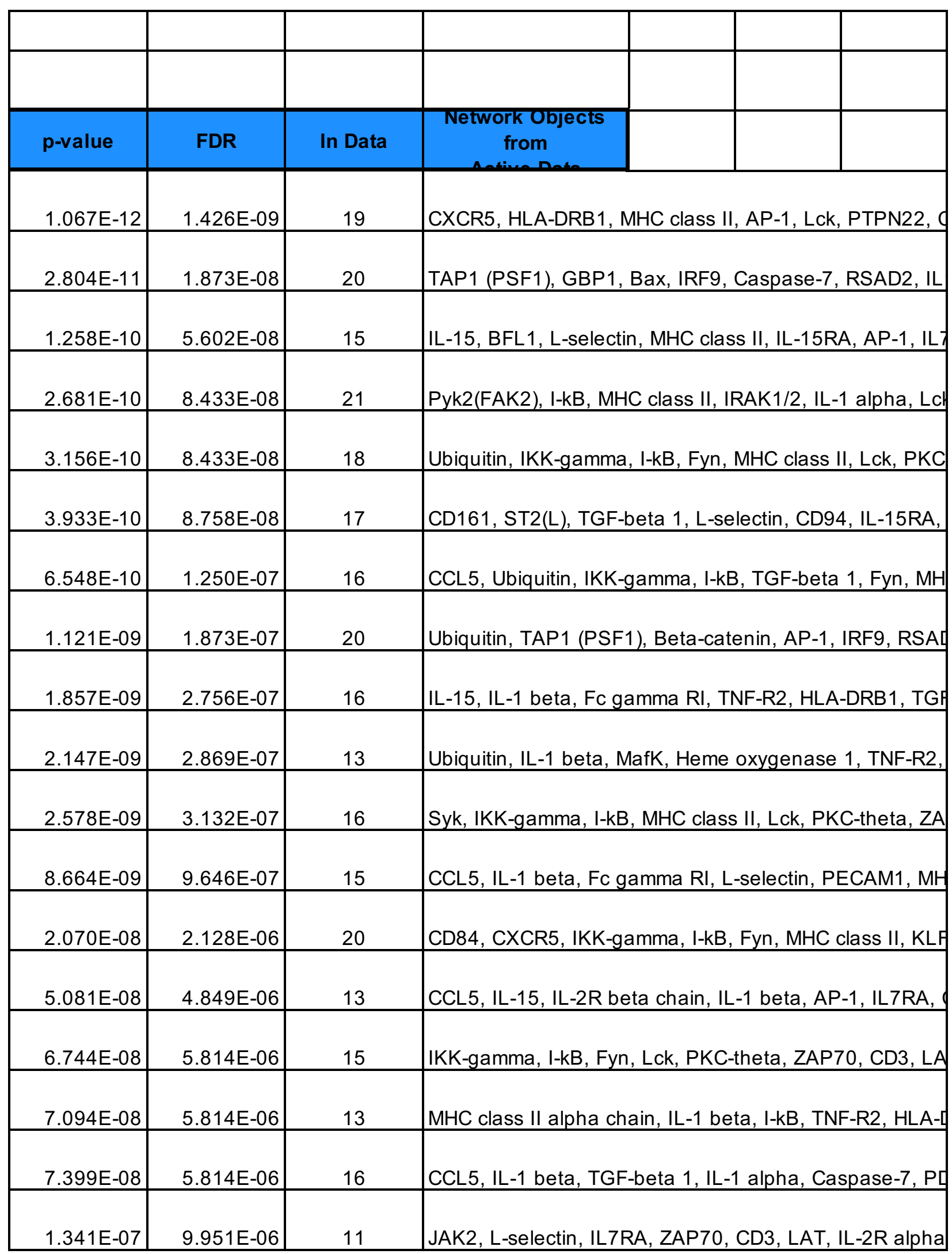




\begin{tabular}{|c|c|c|c|}
\hline $1.461 \mathrm{E}-07$ & $1.027 \mathrm{E}-05$ & 15 & Syk, IL-1 beta, I-kB, TGF-beta 1 , MHC class II, AP-1, Lch \\
\hline $1.595 \mathrm{E}-07$ & $1.066 \mathrm{E}-05$ & 20 & Ubiquitin, I-kB, HLA-DRB1, TNIP1, MHC class II, Lck, PT \\
\hline $1.718 \mathrm{E}-07$ & 1.093E-05 & 12 & PSMB9, TAP1 (PSF1), IRF9, PSMB8(LMP7), Tapasin, It \\
\hline $1.941 \mathrm{E}-07$ & 1.179E-05 & 19 & RXRA, Ephrin-B1, Cyclin D2, KSR1, IKK-gamma, I-kB, J \\
\hline 2.864E-07 & $1.535 \mathrm{E}-05$ & 14 & Syk, MHC class II, PD-L2, Lck, PKC-theta, SMAD3, SLA \\
\hline 2.897E-07 & $1.535 \mathrm{E}-05$ & 16 & CXCR5, IKK-gamma, BFL1, I-kB, PKC-theta, NIK(MAP3I \\
\hline $2.987 \mathrm{E}-07$ & $1.535 \mathrm{E}-05$ & 10 & IL-15, IL-1 beta, MHC class II, CD40(TNFRSF5), CCR7, I \\
\hline 2.987E-07 & $1.535 \mathrm{E}-05$ & 10 & IL-1 beta, TNF-R2, MHC class II, IL-18, Caspase-1, Gran \\
\hline 3.687E-07 & $1.759 \mathrm{E}-05$ & 14 & Ubiquitin, IKK-gamma, IL-1 beta, I-kB, TPL2(MAP3K8), N \\
\hline 3.687E-07 & $1.759 \mathrm{E}-05$ & 14 & Ubiquitin, MafK, Heme oxygenase 1, Fyn, UGT1A1, MAR \\
\hline $3.906 \mathrm{E}-07$ & 1.799E-05 & 17 & Pyk2(FAK2), JAK2, Fyn, PAK, Lck, PLEKHG2, ZAP70, \\
\hline 4.124E-07 & $1.837 \mathrm{E}-05$ & 11 & C-IAP2, c-FLIP(Short), c-FLIP(Long), Bax, Caspase-7, DI \\
\hline 4.715E-07 & $2.032 \mathrm{E}-05$ & 14 & TIM-3, MHC class II, PD-L2, SLAM, CD40(TNFRSF5), CD \\
\hline $5.569 \mathrm{E}-07$ & $2.325 \mathrm{E}-05$ & 13 & COX-2 (PTGS2), JAK2, MHC class II, Lck, CD40(TNFRS \\
\hline $5.816 \mathrm{E}-07$ & $2.355 \mathrm{E}-05$ & 11 & IKK-gamma, I-kB, c-IAP2, c-FLIP(Long), Bax, Caspase- \\
\hline 7.283E-07 & $2.862 \mathrm{E}-05$ & 15 & CCL5, CXCR5, IL-1 beta, I-kB, TNF-R2, TGF-beta 1, MH \\
\hline 8.092E-07 & 2.922E-05 & 11 & Ubiquitin, JAK2, TGF-beta $1, \mathrm{MHC}$ class II, CD40(TNFRS \\
\hline 8.093E-07 & $2.922 \mathrm{E}-05$ & 12 & TGF-beta 1, c-IAP2, c-FLIP(Short), Bax, Caspase-7, DR \\
\hline 8.093E-07 & $2.922 \mathrm{E}-05$ & 12 & COX-2 (PTGS2), GRO-2, IL-1 beta, I-kB, AP-1, IL-1 alph \\
\hline $9.522 \mathrm{E}-07$ & $3.348 \mathrm{E}-05$ & 14 & IL-15, IL-2R beta chain, I-kB, sIL-15RA, IL-15RA, Lck, N \\
\hline $9.790 \mathrm{E}-07$ & 3.354E-05 & 10 & Cyclin D2, BFL1, NIK(MAP3K14), CD137(TNFRSF9), p3 \\
\hline
\end{tabular}




\begin{tabular}{|c|c|c|c|}
\hline $1.071 \mathrm{E}-06$ & $3.576 \mathrm{E}-05$ & 12 & IKK-gamma, I-kB, c-IAP2, jBid, c-FLIP(Short), Bax, Casp \\
\hline 1.404E-06 & 4.576E-05 & 12 & IKK-gamma, IL-1 beta, I-kB, IRAK1/2, AP-1, IRF3, CD40 \\
\hline $1.480 \mathrm{E}-06$ & 4.667E-05 & 14 & PAK3, CXCR5, MHC class II, AP-1, KLF2, FKHR, Bcl-6, \\
\hline 1.509E-06 & 4.667E-05 & 11 & Cyclin D2, TNF-R2, JAK2, TGF-beta 1, Bax, sIL6-RA, HS \\
\hline 1.537E-06 & 4.667E-05 & 18 & COX-2 (PTGS2), S1P1 receptor, TGF-beta 1, CD94, TIE \\
\hline $1.645 \mathrm{E}-06$ & 4.883E-05 & 15 & IRAK2, COX-2 (PTGS2), Ubiquitin, IKK-gamma, IL-1 bet \\
\hline 1.996E-06 & $5.796 \mathrm{E}-05$ & 15 & GRO-2, IKK-gamma, IL-1 beta, Beta-catenin, I-kB, ACTA \\
\hline $2.285 \mathrm{E}-06$ & $6.359 \mathrm{E}-05$ & 9 & Syk, Cyclin D2, IL-2R beta chain, JAK2, C-Myc, IL-2R alp \\
\hline $2.285 \mathrm{E}-06$ & $6.359 E-05$ & 9 & IL-1 beta, I-kB, TNF-R2, MHC class II, CCR7, NIK(MAP3I \\
\hline $2.406 \mathrm{E}-06$ & $6.560 \mathrm{E}-05$ & 13 & IL-15, IL-2R beta chain, IL-1 beta, sIL-15RA, MHC class \\
\hline $2.843 \mathrm{E}-06$ & $7.499 \mathrm{E}-05$ & 18 & COX-2 (PTGS2), PGE2R2, IKK-gamma, IL-1 beta, I-kB, \\
\hline & & & \\
\hline
\end{tabular}




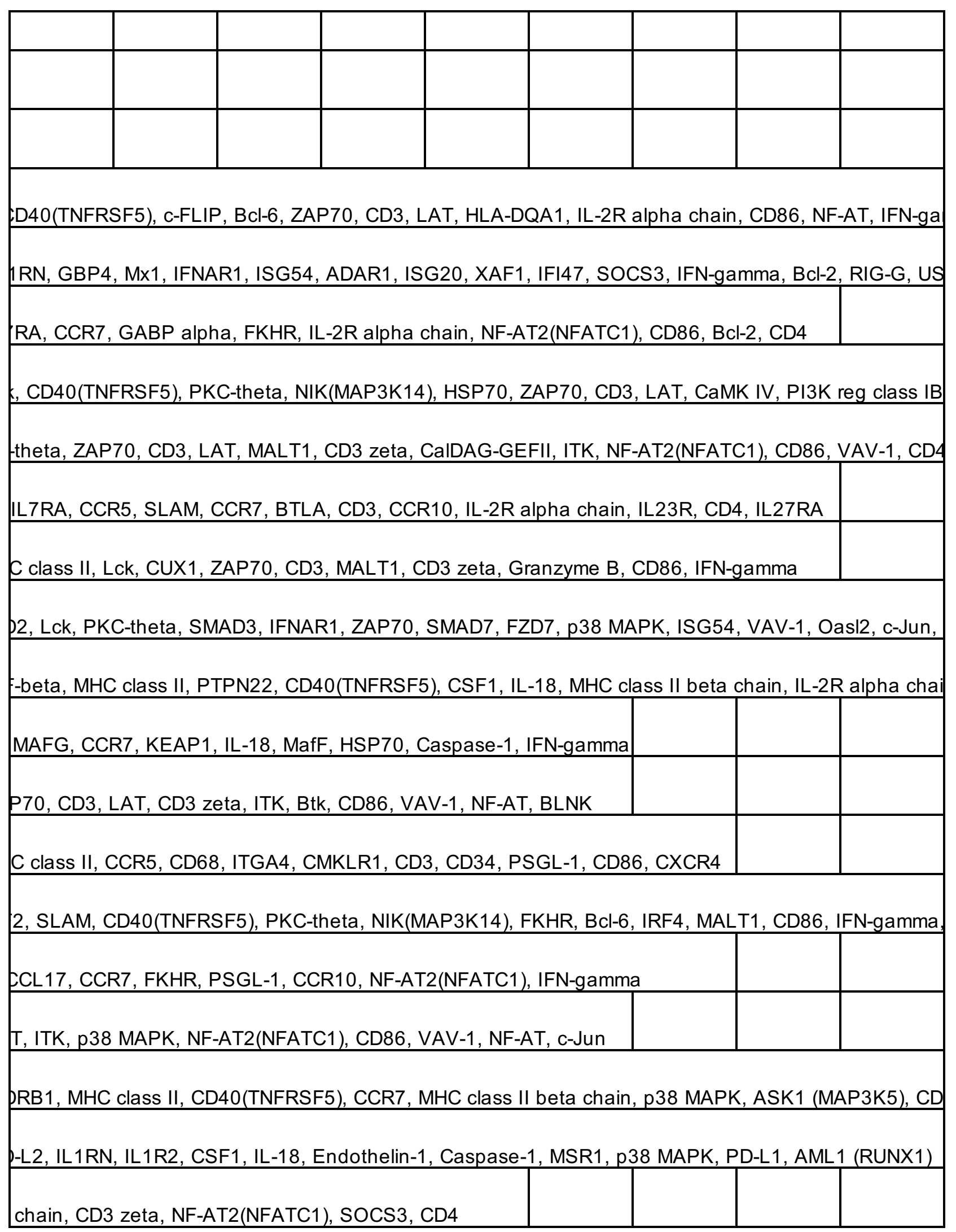


, CD3 epsilon, ZAP70, CD3, LAT, CaMK IV, ETS1, CD3 zeta, CD4

PN22, PKC-theta, NIK(MAP3K14), MHC class II beta chain, ZAP70, CD3, LAT, ETS1, Aiolos, CD3 zeta,

NAR1, HLA-A, c-Myc, TAP, VAV-1, TAP2 (PSF2), c-Jun

AK2, MHC class II, CD40(TNFRSF5), RAR-alpha/RXR-alpha, Bcl-6, c-Myc, IL-2R alpha chain, p38 MAPK

P-130(ADAP), ZAP70, CD3, CD3 zeta, CD86, VAV-1, CD4, PD-L1

(14), FKHR, Bcl-6, CD3, MALT1, IL-2R alpha chain, NF-AT2(NFATC1), CXCR4, IFN-gamma, IL23R, BclL-18, p38 MAPK, CD86, CXCR4, IFN-gamma

zyme B, CD86, IFN-gamma, FasR(CD95), CD4

hHC class II, IRAK1/2, AP-1, CD40(TNFRSF5), HSP70, p38 MAPK, CD86, c-Jun, MD-2

F, GSHB, PKC, KEAP1, MafF, BACH1, GCL reg, SLC7A11, RARalpha

D3, SFK, PI3K reg class IB (p101), TSAD, CD3 zeta, ITK, Btk, VAV-1, CXCR4, G-protein alpha-13 24(TNFRSF10A), c-IAP1, tBid, NFKBIA, FasR(CD95), Bid

137(TNFRSF9), PVR, BTLA, LIGHT(TNFSF14), Galectin-9, CD244, CD30(TNFRSF8), CD86, PD-L1

=5), IL13RA1, ZAP70, CD3, LAT, ITK, NF-AT2(NFATC1), NF-AT, FasR(CD95)

, DR4(TNFRSF10A), c-IAP1, tBid, Bcl-2, Bid

C class II, CCR5, CD40(TNFRSF5), CCR7, CSF1, CMKLR1, M-CSF receptor, IFN-gamma, CD4

F5), SMAD3, TIEG1, IL-2R alpha chain, NF-AT2(NFATC1), CD86, CD4

f(TNFRSF10A), HGF receptor (Met), c-IAP1, tBid, XAF1, Bcl-2, Bid

a, PD-L2, GRO-1, IL-18, GRO-3, c-Jun, PD-L1

K(MAP3K14), PKC-epsilon, c-Myc, ETS1, ADAM17, p38 MAPK, Bcl-2, elF4E

MAPK, ASK1 (MAP3K5), NFKBIA, IFN-gamma, Bcl-2, c-Jun 


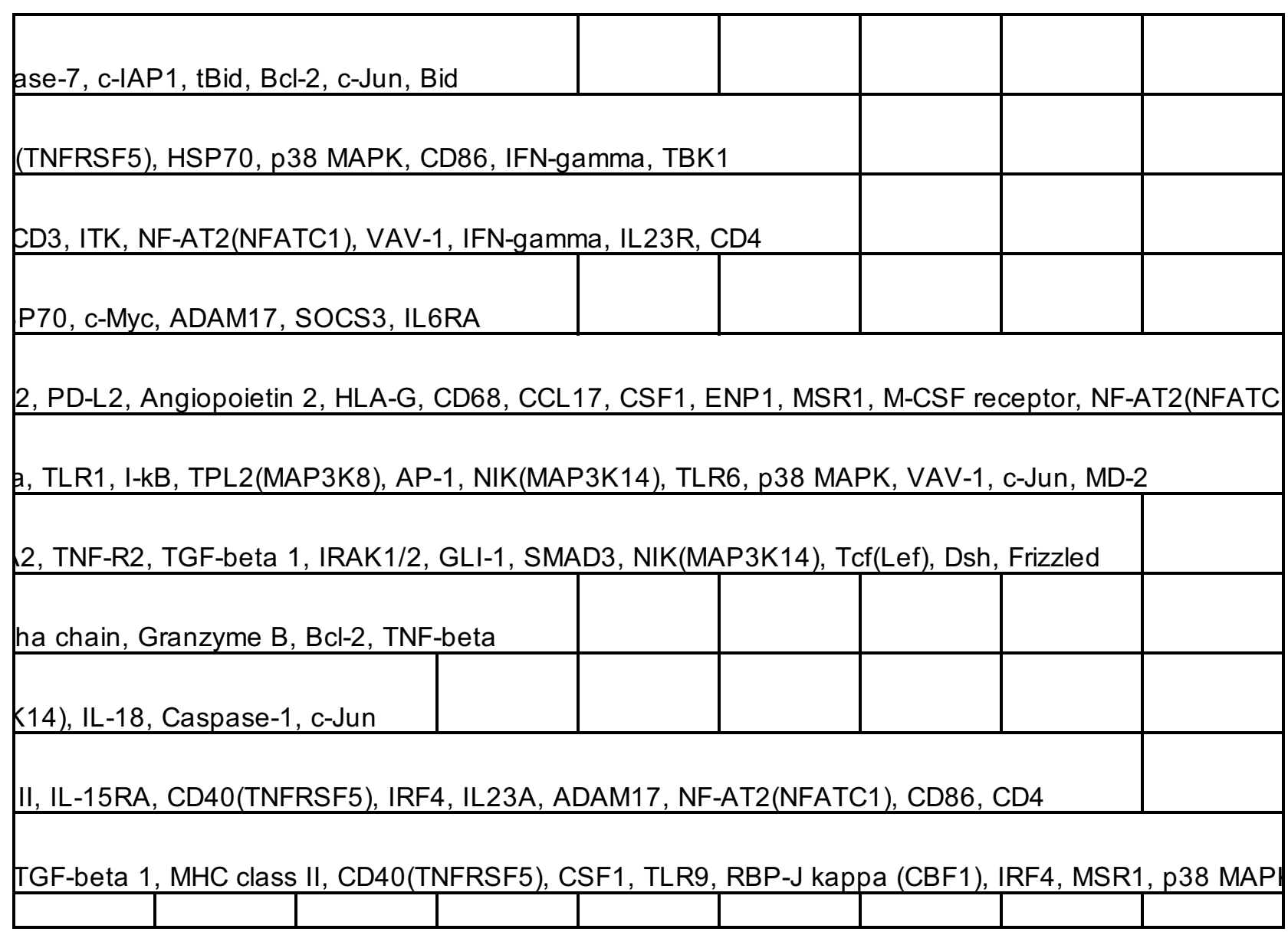




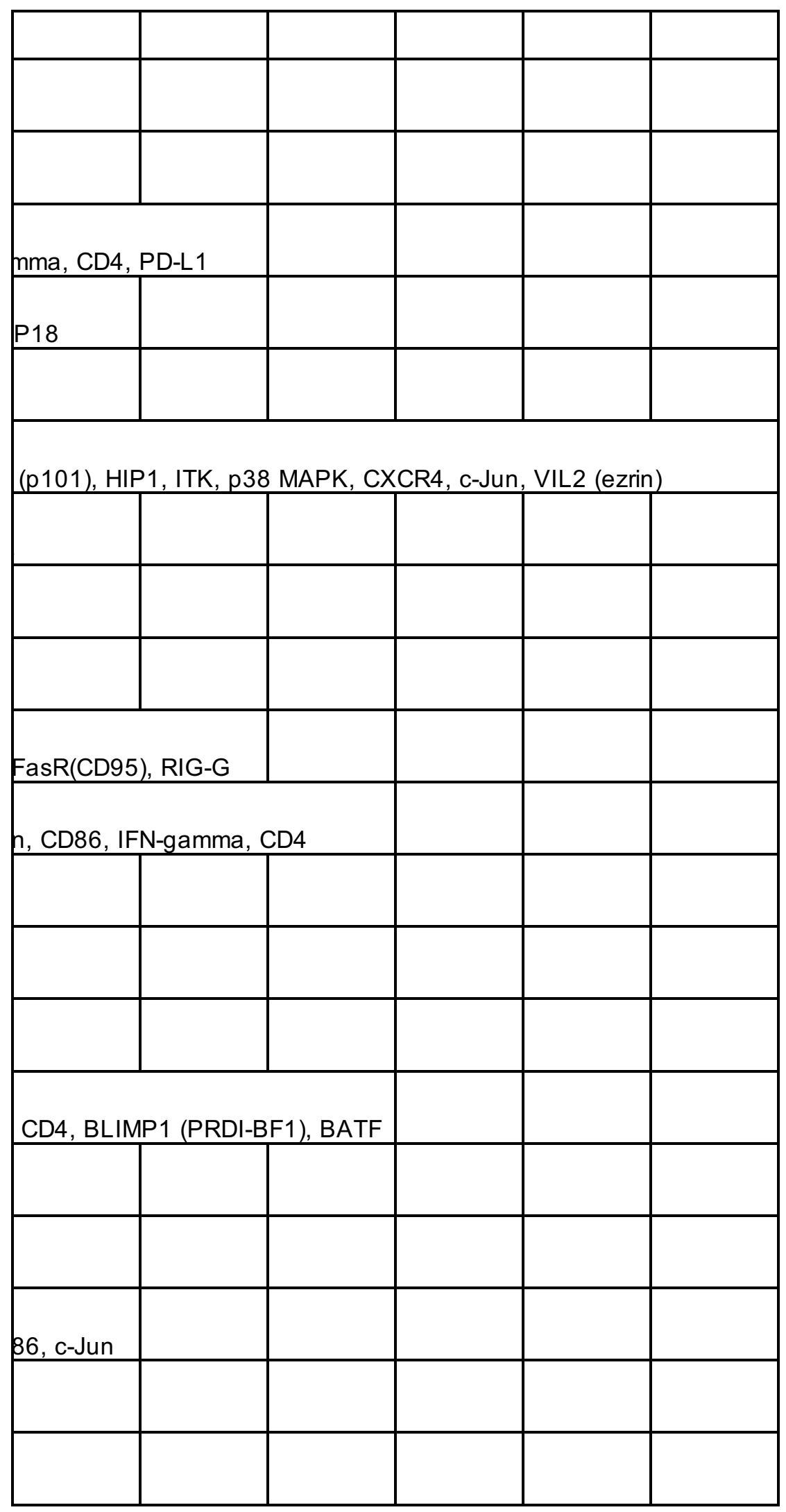




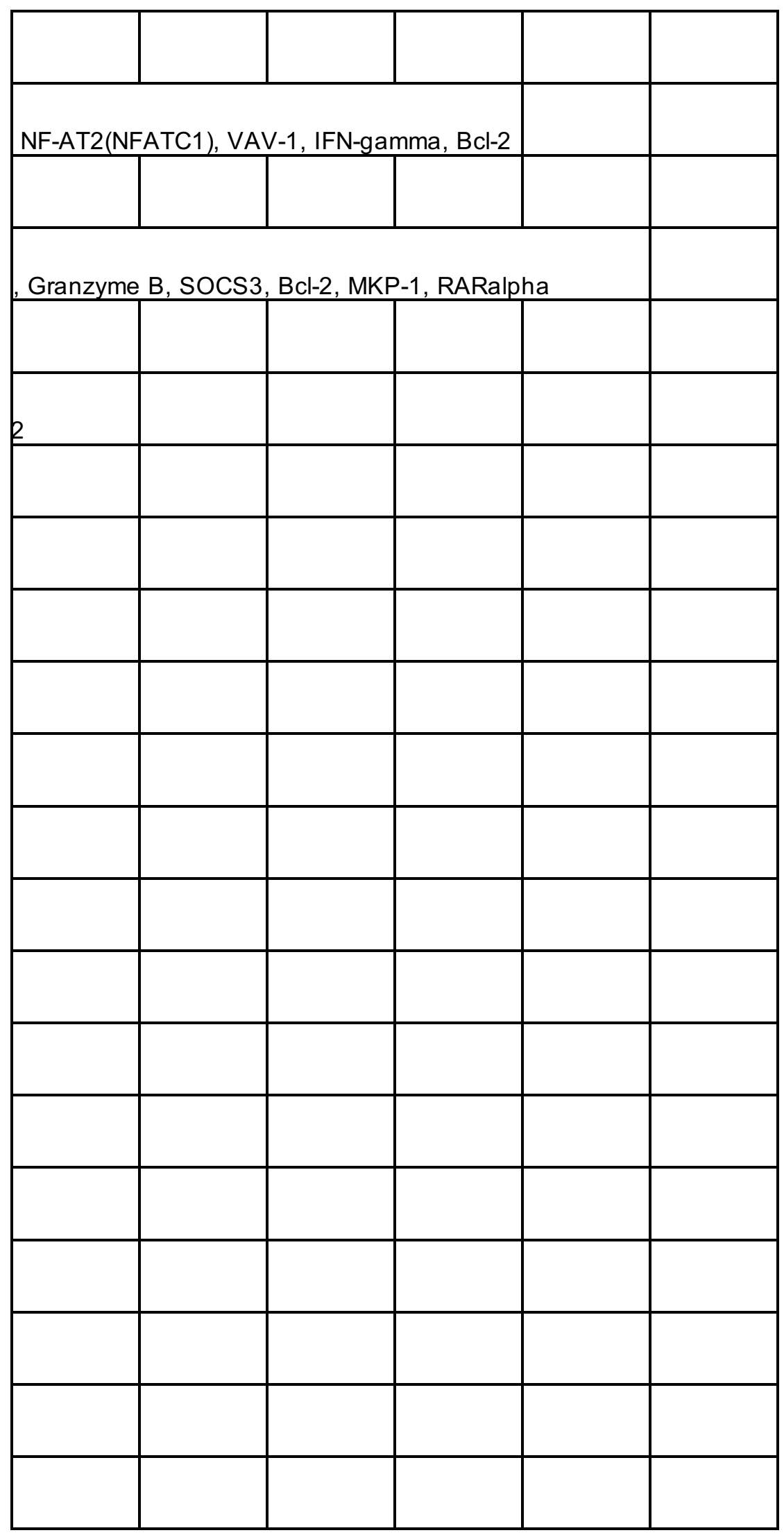


bioRxiv preprint doi: https://doi.org/10.1101/2020.06.30.180927; this version posted July 2, 2020. The copyright holder for this preprint (which was not certified by peer review) is the author/funder. All rights reserved. No reuse allowed without permission.

\begin{tabular}{|l|l|l|l|l|l|}
\hline & & & & & \\
\hline & & & & & \\
\hline & & & & & \\
\hline & & & & & \\
\hline 1), CXCR4, C-Jun, PD-L1 & & & & \\
\hline & & & & & \\
\hline & & & & & \\
\hline & & & & & \\
\hline & & & & & \\
\hline M-CSF receptor, CD86, SOCS3, IFN-gamma & & \\
\hline & & & & & \\
\hline
\end{tabular}

